No.2014-07

\title{
An Equilibrium Foundation of the Soros Chart
}

\author{
Takashi Kano $^{\dagger}$ Hiroshi Morita ${ }^{\ddagger}$ \\ ${ }^{\dagger}$ Hitotsubashi University, Tokyo Center for Economic Research \\ ${ }^{\ddagger}$ Japan Society for the Promotion of Science
}

Current Draft: March 27, 2015

\begin{abstract}
The most prominent characteristic of the Japanese yen/U.S. dollar nominal exchange rate in the post-Plaza Accord era is near random-walk behavior sharing a common stochastic trend with the two-country monetary base differential augmented with excess reserves. In this paper, we develop a simple two-country incomplete-market model equipped with domestic reserve markets to structurally investigate this anecdotal evidence known as the Soros chart. In this model, we theoretically verify that a market discount factor close to one generates near random-walk behavior of an equilibrium nominal exchange rate in accordance with a permanent component of the augmented monetary base differential as an economic fundamental. Results of a Bayesian posterior simulation with post-Plaza Accord data of Japan and the United States plausibly support our model as a data generating process of the Japanese yen/U.S. dollar exchange rate. The model identifies the two-country differential in money demand shocks as the main generator of the sharp depreciation of the Japanese yen against the U.S. dollar under the Abenomics. We discuss data evidence that the identified money demand shocks are tightly correlated with longer-term interest rate differentials between the two countries.
\end{abstract}

Key Words : Japanese yen/U.S. dollar exchange rate; Soros chart; Random walk; Bayesian analysis JEL Classification Number : E31, E37, F41

\footnotetext{
$\dagger$ We would like to thank the editor Shin-ichi Fukuda, an anonymous referee, Kosuke Aoki, Ichiro Fukunaga, Takatoshi Ito, Kazuko Kano, Etsuro Shioji, and conference participants of TCER conference "Abenomics" for helpful and useful discussions and suggestions. Especially, we appreciate Kozo Ueda for his detailed comments on the early draft of this paper. The first author wishes to thank a grant-in-aid for scientific research from the Japan Society for the Promotion of Science (number 24330060). We are solely responsible for any errors and misinterpretations of this paper.

${ }^{\dagger}$ Contacting address: Graduate School of Economics, Hitotsubashi University, Naka 2-1, Kunitachi-city, Tokyo, 1868601, Japan. Emails: tkano@econ.hit-u.ac.jp (T.Kano), hiroshi.morita1013@gmail.com (H.Morita)
} 


\section{Introduction}

Understanding of bumpy unpredictable movements in nominal exchange rates with solid economic reasoning is always a challenging business. Since Meese and Rogoff's (1983) seminal exercise, a random walk has been recognized as a primary property of flexible nominal exchange rates in post-Bretton Woods samples of major advanced economies. ${ }^{1}$ The fact that nominal exchange rates are most described by a naïve random walk statistical model has negated past attempts of academic researchers to enjoy equilibrium models of nominal exchange rates and of policy makers to extract macroeconomic policy implications. Nominal exchange rates resemble a beast that resists a casual explanation stubbornly.

A random walk is also a major characteristic of the Japanese yen/U.S. dollar nominal exchange rate, at least, after the Plaza Accord in 1985. In fact, the serial correlation of the currency return of the Japanese yen against the U.S. dollar is estimated to be statistically low and economically negligible. Moreover, the exchange rate seems to be disconnected with any real economic variables such as output and consumption. Neither common trend nor common cycle does it share with both the output and consumption differentials between the two major exchange rate floaters.

Nevertheless, there are two outstanding statistical properties of the Japanese yen/U.S. dollar exchange rate to be noted for profoundly figuring out nominal exchange rate fluctuations. As the first property, the Soros chart is well-known anecdotal evidence that the Japanese yen/U.S. dollar exchange rate is traced by the two countries' relative money supply. ${ }^{2}$ Figures 1 (a) and (b) are two versions of the Soros chart. The former plots the logarithm of the Japanese yen/U.S. dollar rate (the solid black line) and the differential in the logarithm of the monetary base between Japan and the United States (the dashed blue line). This version of the Soros chart appears unsuccessful. In particular, after 2001 when the Bank of Japan (BOJ) initiated the first quantitative easing (QE) policy, the monetary base differential moves far apart from the Japanese yen/U.S. dollar exchange rate. This failure of the first Soros chart stays obvious even after the Lehman shock with subsequent QE policies conducted by the Federal Reserve System (Fed).

The reason behind the failure of the first version of the Soros chart clearly stems from the massive accumulation of the excess reserves at both the BOJ and the Fed through the unconventional monetary policies after 2001. Figure 1(b) depicts the logarithm of the Japanese yen/U.S. dollar exchange rate (the solid black line) and the two-country differential in the logarithm of the

\footnotetext{
${ }^{1}$ Engel (2014) provides the most recent survey on past studies on nominal exchange rates.

${ }^{2}$ The Soros chart is named after George Soros who pointed out this anecdotal evidence behind the Japanese yen/U.S. dollar nominal exchange rate. See, for example, an article in the Nikkei Shinbun news paper on April 6, 2013 entitled "Kuroda Kanwa: Enyasu kouka wo tsuyoku ishiki (Monetary easing by Mr.Kuroda: Strong intention to the Japanese yen depreciation)"
} 
monetary base subtracted the excess reserve (the dashed blue line). Observe that the augmented Soros chart traces the low-frequency slow-moving component of the exchange rate surprisingly well. It, therefore, is empirically plausible that the augmented monetary base differential shares a common stochastic trend with the exchange rate.

The second outstanding property is the historically tight linkage between the two-county interest rate differential and the low-frequency component of the currency return (i.e., the depreciation rate) of the Japanese yen against the U.S. dollar. Figure 2 displays the differential of the three-month Treasury Bill rates between Japan and the United States (the black line) on the left axis and the currency return of the Japanese yen against the U.S. dollar (the green line) on the right axis, where each time series is demeaned by its own unconditional mean. Notice that the interest rate differential co-moves tightly with the slow-moving component of the currency return, at least, prior to the Lehman shock when the Fed started the zero interest rate policy. This fact suggests that the conventional uncovered interest parity (UIP) condition is likely to capture an important low-frequency property of the Japanese yen/U.S. dollar foreign exchange market in the post-Plaza Accord sample.

In this paper, we develop a simple two-country incomplete-market model that can describe the above major characteristics of the post-Plaza Accord sample of the Japanese yen/U.S. dollar exchange rate. The sample moments that our model targets include (i) the two versions of the Soros chart, i.e., the adjusted monetary base differential forms the stochastic trend of the exchange rate, (ii) the near random-walk behavior of the exchange rate with a negligible serial correlation of the currency return, (iii) the disconnection of the exchange rate with real output and consumption differentials, and (iv) the historically tight linkage between the interest rate differential and the currency return. Recently, Kano (2014) theoretically establishes an equilibrium random-walk property of nominal exchange rates within a canonical two-country incomplete-market model for the post-Bretton Woods sample of Canada and the United States. ${ }^{3}$ In this paper, we extend Kano's (2014) exercise by explicitly modeling money creation processes in the reserve markets of the two countries in order to describe the two versions of the Soros chart jointly. Exploiting the post-Plaza Accord sample of Japan and the United States, we then estimate the proposed two-country model through a Bayesian restricted unobserved component approach. To our best knowledge, this paper is the first attempt to figure out the Soros chart within an equilibrium open-economy model with solid microfoundations.

\footnotetext{
${ }^{3}$ The important predecessors of this paper are Engel and West (2005), Nason and Rogers (2008), and Kano (2014). Engel and West (2005) establish the equilibrium random-walk property in a partial equilibrium asset approach of nominal exchange rates when economic fundamentals are I(1) and the discount factor approaches one. Nason and Rogers (2008) show that the equilibrium random-walk property holds in a two-country incomplete market model. Kano (2014) confirms Nason and Rogers's (2008) claim even when the two-country model of Nason and Rogers is closed suitably to find a balanced growth path with a stationary net foreign asset distribution.
} 
Bayesian posterior inferences support our model as a relevant data generating process for the targeted sample moments. The estimated model mimics the near random-walk Japanese yen/the U.S. dollar rate with the augmented Soros chart as a common stochastic trend. Importantly, transitory deviations of the exchange rate from the augmented Soros chart are dominated by the two-country permanent money demand shocks. In particular, the sharp depreciation of the Japanese yen against the U.S. dollar after 2012Q4 is explained by these money demand shocks. We provide and discuss data evidence that the estimated money demand shocks are tightly correlated with longer-term interest rate differentials between the two countries when most market participants expected that the extremely easing monetary policy of the BOJ would be conducted by Governor Kuroda in accordance with Prime Minister Abe as his new economic policy subsequently known as the "Abenomics." This empirical fact suggests that long-run expectations on the two-country differential in interest rates - more fundamentally, market's expectations toward the two-country differential in monetary policy regimes in the long run — should be the main driver of the sharp yen depreciation against the U.S. dollar produced by the Abenomics.

The organization of the rest of the paper is as follows. Section 2 introduces our two-country model. Section 3 establishes the equilibrium random walk property of the nominal exchange rate. Section 4 describes the Bayesian unobserved component approach of this paper and reports the empirical results. Section 5 concludes.

\section{A two-country incomplete-market model for the Soros chart}

\subsection{The model}

In this paper, we extend a canonical incomplete market model with two countries, which is investigated in Kano (2014), to study the Soros chart. Consider the home and foreign countries indexed by $i=h, f$. Each country is endowed with a representative household whose objective function is the lifetime money-in-utility

$$
\sum_{j=0}^{\infty} \beta^{j} E_{t}\left\{\ln C_{i, t+j}+\Gamma_{i, t+j} \ln \left(\frac{M_{i, t+j}^{d}}{P_{i, t+j}}\right)\right\}, \quad 0<\beta<1, \quad \text { for } i=h, f,
$$

where $C_{i, t}, M_{i, t}^{d}$, and $P_{i, t}$ represent the consumption, money demand, and price index of country $i$, respectively. The money-in-utility function is subject to money demand shock $\Gamma_{i, t}$. The representative households in the home and foreign countries maximize their lifetime utility functions subject to the home budget constraint

$B_{h, t}^{h}+S_{t} B_{h, t}^{f}+P_{h, t} C_{h, t}+M_{h, t}^{d}=\left(1+r_{h, t-1}^{h}\right) B_{h, t-1}^{h}+S_{t}\left(1+r_{h, t-1}^{f}\right) B_{h, t-1}^{f}+M_{h, t-1}^{d}+P_{h, t} Y_{h, t}+T_{h, t}$, 
and its foreign counterpart

$$
\frac{B_{f, t}^{h}}{S_{t}}+B_{f, t}^{f}+P_{f, t} C_{f, t}+M_{f, t}^{d}=\left(1+r_{f, t-1}^{h}\right) \frac{B_{f, t-1}^{h}}{S_{t}}+\left(1+r_{f, t-1}^{f}\right) B_{f, t-1}^{f}+M_{f, t-1}^{d}+P_{f, t} Y_{f, t}+T_{f, t},
$$

respectively, where $B_{i, t}^{l}, r_{i, t}^{l}, Y_{i, t}, T_{i, t}$, and $S_{t}$ denote country $i$ 's holdings of country l's nominal bonds at the end of period $t$, county $i$ 's returns on country l's bonds, country $i$ 's output level, country $i$ 's government transfers, and the bilateral nominal exchange rate of the home currency in terms of the foreign currency, respectively. Hence, an increase (decrease) in $S_{t}$ means a depreciation (appreciation) of the home currency against the foreign currency. Each country's output $Y_{i, t}$ is given as an exogenous endowment following stochastic process $Y_{i, t}=y_{i, t} A_{i, t}$, where $y_{i, t}$ is the transitory component and $A_{i, t}$ is the permanent component. Below, we interpret permanent component $A_{i, t}$ as the total factor productivity (TFP) in the underlying production technology.

The first-order necessary conditions (FONCs) of the home country's representative household are given by the above budget constraint, the Euler equation

$$
\frac{1}{P_{h, t} C_{h, t}}=\beta\left(1+r_{h, t}^{h}\right) E_{t}\left(\frac{1}{P_{h, t+1} C_{h, t+1}}\right)
$$

the utility-based uncovered interest rate parity condition (UIP)

$$
\left(1+r_{h, t}^{h}\right) E_{t}\left(\frac{1}{P_{h, t+1} C_{h, t+1}}\right)=\frac{\left(1+r_{h, t}^{f}\right)}{S_{t}} E_{t}\left(\frac{S_{t+1}}{P_{h, t+1} C_{h, t+1}}\right),
$$

and the money demand function

$$
\frac{M_{h, t}^{d}}{P_{h, t}}=\Gamma_{h, t}\left(\frac{1+r_{h, t}^{h}}{r_{h, t}^{h}}\right) C_{h, t} .
$$

The foreign country's counterparts of the FONCs are the budget constraint, the Euler equation

$$
\frac{1}{P_{f, t} C_{f, t}}=\beta\left(1+r_{f, t}^{f}\right) E_{t}\left(\frac{1}{P_{f, t+1} C_{f, t+1}}\right)
$$

the utility-based uncovered interest parity parity condition (UIP)

$$
\left(1+r_{f, t}^{h}\right) E_{t}\left(\frac{1}{S_{t+1} P_{f, t+1} C_{f, t+1}}\right)=\frac{\left(1+r_{f, t}^{f}\right)}{S_{t}} E_{t}\left(\frac{1}{P_{f, t+1} C_{f, t+1}}\right),
$$

and the money demand function

$$
\frac{M_{f, t}^{d}}{P_{f, t}}=\Gamma_{f, t}\left(\frac{1+r_{f, t}^{f}}{r_{f, t}^{f}}\right) C_{f, t} .
$$

Notice that $\Gamma_{i, t}$ for $i=h, f$ is an additive shock to the logarithm of the money demand function. 
The most important extension of our model from Kano's (2014) is found in the explicit modeling of a money creation process, which specifies the linkage among money supply $M_{i, t}$, monetary base $H_{i, t}$, and excess reserve $E R_{i, t}$ in country $i=h, f$. The monetary base consists of cash in circulation $V_{i, t}$, required reserve $R R_{i, t}$, and excess reserve $E R_{i, t}$ held by private banks in the accounts at the central bank of each country:

$$
H_{i, t}=V_{i, t}+R R_{i, t}+E R_{i, t}, \quad \text { for } i=h, f .
$$

The money supply is defined as the sum of the cash in circulation and demand deposit at private banks denoted by $D_{i, t}$ :

$$
M_{i, t}=V_{i, t}+D_{i, t}, \quad \text { for } i=h, f .
$$

Let $v_{i, t} \in(0,1)$ denote the ratio of the cash to the deposit, $V_{i, t} / D_{i, t}$. Similarly, let $r r_{i, t} \in(0,1)$ denote the required reserve rate, $R R_{i, t} / D_{i, t}$. From eqs (1) and (2), we can derive the following money creation process

$$
M_{i, t}=\Psi_{i, t}\left(H_{i, t}-E R_{i, t}\right)=\Psi_{i, t}\left(1-e r_{i, t}\right) H_{i, t},
$$

where $\Psi_{i, t}=\left(1+v_{i, t}\right) /\left(r r_{i, t}+v_{i, t}\right)>1$ is the money multiplier and $e r_{i, t}$ is the ratio of the excess reserve to the monetary base, $E R_{i, t} / H_{i, t}$. Eq.(3) relies on our presumption that the excess reserve is leaked out from the money creation process. In this paper, we assume that both the money multiplier and the excess reserve ratio follow exogenous stochastic processes that we specify below more in details. ${ }^{4}$

The central bank of country $i$ controls for the monetary base. We decompose the monetary base into permanent and transitory components $H_{i, t}^{\tau}$ and $h_{i, t}: H_{i, t} \equiv h_{i, t} H_{i, t}^{\tau}$. From eq.(3), the money supply also consists of permanent and transitory components, $\Psi_{i, t}\left(1-e r_{i, t}\right) H_{i, t}^{\tau}$ and $h_{i, t}:{ }^{5}$

$$
M_{i, t}=h_{i, t} \Psi_{i, t}\left(1-e r_{i, t}\right) H_{i, t}^{\tau} .
$$

The government in each country transfers the seigniorage collected through money creation process (3) to the household in a lump-sum manner. Hence, the government's budget constraint is

$$
M_{i, t}-M_{i, t-1}=T_{i, t}, \quad \text { for } i=h, f .
$$

\footnotetext{
${ }^{4}$ This assumption of the exogenous money multiplier and excess reserve, of course, is counterfactual and it would be better to endogenize the determination of them for understanding the reserve markets of the two countries profoundly. This assumption prevents from deriving a realistic monetary policy implication on the exchange rate from the model. Nevertheless, we think that this extreme assumption is innocuous to the primary purpose of this paper, which is not to describe the monetary policy frameworks and their transmission mechanisms of the two countries precisely, but to replicate the empirical fact that the adjusted monetary base differential forms the stochastic trend of the near random-walk Japanese yen/U.S. dollar exchange rate within a two-country model as parsimonious as possible. For this purpose, taking a strategy of explaining the money multiplier and the excess reserves by independent exogenous stochastic processes, we rather focus on the endogenous determination of the near random-walk exchange rate. We appreciate Kozo Ueda's correctly pointing out this limitation of the paper.

${ }^{5}$ Therefore, the permanent component of the money supply depends on the money multiplier that also relies on the household's portfolio choice between the cash and the demand deposit.
} 
To close the model within an incomplete international financial market, we allow for a debt-elastic risk premium in the interest rates faced only by the home country:

$$
r_{h, t}^{l}=r_{w, t}^{l}\left[1+\psi\left\{\exp \left(-b_{h, t}^{l}+\bar{d}\right)-1\right\}\right], \quad \bar{d} \leq 0, \quad \psi>0, \quad \text { for } \quad l=h, f
$$

where $r_{w, t}^{l}$ is the equilibrium world interest rate of country l's bond and $b_{h, t}^{l}$ is the transitory component of the home country's holdings of country l's bonds, $B_{h, t}^{l} \Gamma_{l, t} / \Psi_{l, t}\left(1-e r_{l, t}\right) H_{l, t}^{\tau}$. Notice that the home country needs to pay a risk premium over the world interest rate level $r_{w, t}^{i}$ when the transitory components of the home country's net borrowing positions $B_{h, t}^{l} \Gamma_{l, t} / \Psi_{l, t}\left(1-e r_{l, t}\right) H_{l, t}^{\tau}<0$ is beyond its threshold level $\bar{d}$. The risk premium is given as an externality: the household does not take into account the effect of the debt position on the risk premium when maximizing the lifetime utility function. On the other hand, we do not attach a risk premium to foreign country's interest rates: $r_{f, t}^{l}=r_{w, t}^{l}$ for $l=h, f .^{6}$

The purchasing power parity (PPP) is assumed to hold only up to a persistent PPP deviation shock $q_{t}$ :

$$
S_{t} P_{f, t}=P_{h, t} q_{t}
$$

The market-clearing conditions of the two countries' bond markets are

$$
B_{h, t}^{h}+B_{f, t}^{h}=0 \quad \text { and } \quad B_{h, t}^{f}+B_{f, t}^{f}=0,
$$

i.e., along an equilibrium path, the world net supply of nominal bonds is zero on a period-by-period basis. Finally the money demand should be equal to the money supply, $M_{i, t}^{d}=M_{i, t}$ for $i=h, f$.

As claimed by Kano (2014), to find a balanced growth path in the two-country incomplete market model, the permanent TFPs of the two countries need to be cointegrated in the long run. For this purpose, we assume that the logarithm of the TFP of each country is $\mathrm{I}(1)$ and the cross-country TFP differential, $\ln a_{t} \equiv \ln A_{h, t} / A_{f, t}$, is $\mathrm{I}(0)$. This assumption requires that the two countries' TFPs must be cointegrated. Hence, we specify the TFP processes as the following error correction models (ECMs)

$$
\begin{gathered}
\Delta \ln A_{h, t}=\ln \gamma_{A}-\frac{\lambda}{2}\left(\ln A_{h, t-1}-\ln A_{f, t-1}\right)+\epsilon_{A, t}^{h}, \\
\Delta \ln A_{f, t}=\ln \gamma_{A}+\frac{\lambda}{2}\left(\ln A_{h, t-1}-\ln A_{f, t-1}\right)+\epsilon_{A, t}^{f},
\end{gathered}
$$

where $\gamma_{A}>1$ is the common drift term and $\lambda \in[0,1)$ is the adjustment speed of the error correction mechanism. $\epsilon_{A, t}^{h}$ and $\epsilon_{A, t}^{f}$, respectively, are i.i.d. shocks to the home and foreign TFPs. The ECMs of the TFPs imply that the cross-country TFP differential is $\mathrm{I}(0)$ because

$$
\ln a_{t}=(1-\lambda) \ln a_{t-1}+\epsilon_{A, t},
$$

\footnotetext{
${ }^{6}$ Since the elasticity of the risk premium toward the debt position, $\psi$, is set to a very small number, this asymmetric treatment of the debt elastic risk premium between the home and foreign countries does not affect the equilibrium outcome much.
} 
where $\epsilon_{A, t} \equiv \epsilon_{A, t}^{h}-\epsilon_{A, t}^{f}$ is the cross-country TFP shock differential. Importantly, if the adjustment speed $\lambda$ is sufficiently close to zero, the cross-country TFP differential can be realized near I(1), as maintained by Nason and Rogers (2008).

We assume the logarithm of the permanent component of the monetary base of each country, $\ln H_{i, t}^{\tau}$, to be I(1). Moreover, we allow for a two-period ahead news shock to the permanent component of the monetary base, $\xi_{t}^{i}$, to identify anticipated permanent changes in the monetary policy. ${ }^{7}$ We then specify each country's monetary base growth rate $\Delta \ln H_{i, t}^{\tau} \equiv \ln \gamma_{H, t}^{i}$ by the following stochastic process:

$$
\ln \gamma_{H, t}^{i}=\left(1-\rho_{H}\right) \ln \gamma_{H}+\rho_{H} \ln \gamma_{H, t-1}^{i}+\xi_{t-2}^{i}+\epsilon_{H, t}^{i}, \quad 0<\rho_{H}<1, \quad \text { for } i=h, f,
$$

where $\ln \gamma_{H}$ is the mean of the monetary base growth rate common to the two countries. News shock $\xi_{t}^{i}$ is assumed to an i.i.d. shock, $\epsilon_{\xi, t}^{i}$. Importantly, this specification implies that the cross-country differential in the permanent component of the monetary base, $\ln H_{t}^{\tau} \equiv \ln H_{h, t}^{\tau} / H_{f, t}^{\tau}$ is I(1). The fraction of the non-excess reserve component in the total monetary base, $\ln \left(1-e r_{i, t}\right)$, is also assumed to be $\mathrm{I}(1)$ and so is the corresponding cross-country differential, $\ln \left(1-e r_{t}\right) \equiv \ln \left(1-e r_{h, t}\right) /\left(1-e r_{f, t}\right)$. $^{8}$ Therefore, we specify the growth rate of each country's non-excess reserve component of the total monetary base $\Delta \ln \left(1-e r_{i, t}\right) \equiv \ln \gamma_{e r, t}^{i}$ to be independent $\operatorname{AR}(1)$ process:

$$
\ln \gamma_{e r, t}^{i}=\left(1-\rho_{e r}\right) \ln \gamma_{e r}+\rho_{e r} \ln \gamma_{e r, t-1}^{i}+\zeta_{t-2}^{i}+\epsilon_{e r, t}^{i}, \quad 0<\rho_{e r}<1, \quad \text { for } i=h, f .
$$

where $\ln \gamma_{e r}$ is the mean of the fraction of the non-excess reserve component in the total monetary base common to the two countries, $\zeta_{t}^{i}$ is a two-period ahead news shock to the non-excess reserve component. News shock $\zeta_{t}^{i}$ is assumed to an i.i.d. white noise shock, $\epsilon_{\zeta, t}^{i}$.

We characterize the stochastic processes of the money demand shock and money multiplier, $\Gamma_{i, t}$ and $\Psi_{i, t}$, jointly as a single I(1) permanent stochastic process. Let define a new variable $\Phi_{i, t}$ by ratio $\Gamma_{i, t} / \Psi_{i, t}$ for $i=h, f$. The growth rate of the variable, $\Delta \ln \Phi_{i, t} \equiv \ln \gamma_{\Phi, t}^{i}$, then is assumed to follow

$$
\ln \gamma_{\Phi, t}^{i}=\rho_{\Phi} \ln \gamma_{\Phi, t-1}^{i}+\epsilon_{\Phi, t}^{i}, \quad 0<\rho_{\Phi}<1, \quad \text { for } i=h, f .
$$

Below we call $\Phi_{i, t}$ the money market shock throughout the paper. ${ }^{9}$

The stochastic processes of the other structural shocks are assumed to be stationary. The logarithm of the transitory output component for each country, $\ln y_{i, t}$, is specified as the following

\footnotetext{
${ }^{7}$ That is, news shock $\xi_{t}$ is a shock to the future permanent component of the monetary base $\ln H_{i, t+2}^{\tau}$, which is realized at period $t$.

${ }^{8}$ Because, by construction, $\ln \left(1-e r_{i, t}\right)$ is a bounded sequence, its specification by an $\mathrm{I}(1)$ process is, in fact, statistically irrelevant. It is not obvious and quite difficult to find a suitable stationary process to fit to the data of the excess reserves in Japan and the U.S. Hence, in this paper, we tract the data of the excess reserves in the two countries by independent stochastic trends.

${ }^{9}$ As pointed out by an anonymous referee, it should be noted that money market shock $\Phi_{i, t}$ is a mixture of demand and supply shifters in the money market, i.e., money demand shock $\Gamma_{i, t}$ and money multiplier $\Psi_{i, t}$.
} 
$\operatorname{AR}(1)$ process:

$$
\ln y_{i, t}=\left(1-\rho_{y}\right) \ln y_{i}+\rho_{y} \ln y_{i, t-1}+\epsilon_{y, t}^{i}, \quad 0<\rho_{y}<1, \quad \text { for } i=h, f .
$$

Similarly, the stochastic process of the logarithm of the transitory monetary base component for each country, $\ln h_{i, t}$, is specified as the following $\operatorname{AR}(1)$ process:

$$
\ln h_{i, t}=\rho_{h} \ln h_{i, t-1}+\epsilon_{h, t}^{i}, \quad 0<\rho_{h}<1, \quad \text { for } i=h, f
$$

The PPP shock $q_{t}$ follows an $\mathrm{AR}(1)$ process in term of the logarithm:

$$
\ln q_{t}=\rho_{q} \ln q_{t-1}+\epsilon_{q, t}, \quad 0<\rho_{q}<1 .
$$

Throughout this paper, we assume that all structural shocks are distributed independently.

\section{Equilibrium random-walk property}

We now show that the exchange rate could follow a near random-walk in this two-country general equilibrium model. To prove this proposition, we characterize an approximated analytical solution of the depreciation rate in the case of symmetric two countries: $\bar{d}=0$ and $y=y_{h}=y_{f}$. Our strategy of derivation is the following. We first stochastically de-trend the FONCs by stochastic trends. We then take a log-linear approximation of the simultaneous equation system consisting of the stochastically de-trended FONCs to derive the corresponding linear rational expectations (LRE) model. Below we show that under the symmetric two-country assumption, the whole LRE system is simply degenerated to a system of three expectational difference equations with respect to only relative variables between the two countries. The approximated analytical solution of the depreciation rate is then fully characterized by unwinding stochastic trends in a unique saddle path of the stochastically de-trended three-equation LRE system.

Define the stochastically de-trended versions of consumption, the price index, the bond holdings, and the exchange rate as $c_{i, t} \equiv C_{i, t} / A_{i, t}, p_{i, t} \equiv P_{i, t} A_{i, t} \Phi_{i, t} /\left[\left(1-e r_{i, t}\right) H_{i, t}^{\tau}\right], b_{i, t}^{l} \equiv$ $B_{i, t}^{l} \Phi_{l, t} /\left[\left(1-e r_{l, t}\right) H_{l, t}^{\tau}\right]$, and $s_{t} \equiv S_{t} H_{f, t}^{\tau}\left(1-e r_{f, t}\right) \Phi_{h, t} /\left[H_{h, t}^{\tau}\left(1-e r_{h, t}\right) \Phi_{f, t}\right]$, respectively. Define also the growth rates of the TFP, the permanent monetary base, the non-excess reserve component of the monetary base, and the money market shock as $\gamma_{A, t}^{i} \equiv A_{i, t} / A_{i, t-1}, \gamma_{H, t}^{i} \equiv H_{i, t}^{\tau} / H_{i, t-1}^{\tau}$, $\gamma_{e r, t}^{i} \equiv\left(1-e r_{i, t}\right) /\left(1-e r_{i, t-1}\right)$, and $\gamma_{\Phi, t}^{i} \equiv \Phi_{i, t} / \Phi_{i, t-1} \cdot{ }^{10}$ Let $c_{t}$ and $h_{t}$ denote the de-trended consumption ratio and the transitory monetary base ratio between the two countries, $c_{t} \equiv c_{h, t} / c_{f, t}$ and

\footnotetext{
${ }^{10}$ In Appendix A, we summarize the stochastically de-trended FONCs of the home and foreign countries. The resulting ten equations determine the ten endogenous variables $c_{h, t}, c_{f, t}, p_{h, t}, s_{t}, b_{h, t}^{h}, b_{h, t}^{f}, r_{h, t}^{h}, r_{h, t}^{f}, r_{w, t}^{h}$, and $r_{w, t}^{f}$, given nine exogenous variables $\gamma_{H, t}^{h}, \gamma_{H, t}^{f}, \gamma_{e r, t}^{h}, \gamma_{e r, t}^{f}, \gamma_{\Phi, t}^{h}, \gamma_{\Phi, t}^{f}, a_{t}, h_{h, t}, h_{f, t}, y_{h, t}$, and $y_{f, t}$.
} 
$h_{t} \equiv h_{h, t} / h_{f, t}$. Furthermore, let $\gamma_{H, t} \equiv \gamma_{H, t}^{h} / \gamma_{H, t}^{f}, \gamma_{e r, t} \equiv \gamma_{e r, t}^{h} / \gamma_{e r, t}^{f}$, and $\gamma_{\Phi, t} \equiv \gamma_{\Phi, t}^{h} / \gamma_{\Phi, t}^{f}$ describe the relative growth rates of the permanent component of monetary base, the non-excess reserve portion of the total monetary base, and the money market shock, respectively.

To characterize the three-equation LRE system of the model, define as $\hat{x}_{t}$ a percentage deviation of any variable $x_{t}$ from its deterministic steady state value $x^{*}, \hat{x}_{t} \equiv \ln x_{t}-\ln x^{*}$ and as $\tilde{x}_{t}$ a deviation of $x_{t}$ from its deterministic steady state, $\tilde{x}_{t}=x_{t}-x^{*}{ }^{11}$ Below, the steady state value of the nominal market discount factor is denoted by $\kappa \equiv 1 /\left(1+r^{*}\right)=\beta / \mu$ where $\mu \equiv \gamma_{H} \gamma_{e r}$. As explained in Appendix B, the log-linear approximated system of the stochastically de-trended FONCs then is degenerated to the following system of three expectational difference equations:

$$
\begin{aligned}
& \hat{s}_{t}=\kappa E_{t} \hat{s}_{t+1}-(1-\kappa)\left(\hat{c}_{t}+\hat{a}_{t}-\hat{h}_{t}-\hat{q}_{t}\right)+\kappa E_{t}\left(\hat{\gamma}_{H, t+1}+\hat{\gamma}_{e r, t+1}-\hat{\gamma}_{\Phi, t+1}\right)-\psi \kappa(1-\kappa) \tilde{b}_{t}, \\
& \hat{a}_{t}+\hat{s}_{t}+\hat{c}_{t}-\hat{q}_{t}=\kappa E_{t}\left(\hat{a}_{t+1}+\hat{s}_{t+1}+\hat{c}_{t+1}-\hat{q}_{t+1}\right)+(1-\kappa) \hat{h}_{t}+\kappa E_{t}\left(\hat{\gamma}_{H, t+1}+\hat{\gamma}_{e r, t+1}-\hat{\gamma}_{\Phi, t+1}\right), \\
& \tilde{b}_{t}=\beta^{-1} \tilde{b}_{t-1}+p_{h}^{*} y^{*}\left(\hat{y}_{t}-\hat{c}_{t}\right),
\end{aligned}
$$

where $y^{*} \equiv y / 4, \hat{\gamma}_{H, t} \equiv \hat{\gamma}_{H, t}^{h}-\hat{\gamma}_{H, t}^{f}, \hat{\gamma}_{e r, t} \equiv \hat{\gamma}_{e r, t}^{h}-\hat{\gamma}_{e r, t}^{f}$, and $\hat{\gamma}_{\Phi, t} \equiv \hat{\gamma}_{\Phi, t}^{h}-\hat{\gamma}_{\Phi, t}^{f}$. Specifically, the first equation represents the stochastically de-trended UIP; the second equation the cross-country difference in the Euler equation; and the third equation the law of motion of net foreign asset position after solving the interest rate differential through the money demand functions of the two countries. LRE system (4) then has a unique saddle path of the de-trended exchange rate as a linear function of state variables $\tilde{b}_{t-1}, \hat{a}_{t}, \hat{h}_{t}, \hat{y}_{t}, \hat{q}_{t}, \xi_{t}, \hat{\gamma}_{H, t}, \hat{\gamma}_{e r, t}, \hat{\gamma}_{\Phi, t}, \xi_{t}, \xi_{t-1}, \zeta_{t}, \zeta_{t-1}$ :

$$
\begin{aligned}
\hat{s}_{t}= & \frac{\beta \eta-1}{\beta p_{h}^{*} y^{*}} \tilde{b}_{t-1}+\frac{\beta \eta-1}{1-\beta \eta(1-\lambda)} \hat{a}_{t}+\frac{1-\kappa}{1-\kappa \rho_{h}} \hat{h}_{t}+\frac{\beta \eta-1}{1-\beta \eta \rho_{y}} \hat{y}_{t}-\frac{\beta \eta-1}{1-\beta \eta \rho_{q}} \hat{q}_{t}+\frac{\kappa \rho_{H}}{1-\kappa \rho_{H}} \hat{\gamma}_{H, t} \\
& +\frac{\kappa}{1-\kappa \rho_{H}} \xi_{t-1}+\frac{\kappa^{2}}{1-\kappa \rho_{H}} \xi_{t}+\frac{\kappa \rho_{e r}}{1-\kappa \rho_{e r}} \hat{\gamma}_{e r, t}+\frac{\kappa}{1-\kappa \rho_{e r}} \zeta_{t-1}+\frac{\kappa^{2}}{1-\kappa \rho_{e r}} \zeta_{t}-\frac{\kappa \rho_{\Phi}}{1-\kappa \rho_{\Phi}} \hat{\gamma}_{\Phi, t},
\end{aligned}
$$

where constant $\eta<1$ is one of the two roots of the second order expectational differential equation of the de-trended net foreign asset position $\tilde{b}_{t}$. Constant $\eta$ approaches one at the limit of $\kappa \rightarrow 1$.

Recall that after unwinding stochastic trends, the de-trended exchange rate $\hat{s}_{t}$ characterizes the equilibrium depreciation rate $\Delta \ln S_{t}$ by

$$
\begin{aligned}
\Delta \ln S_{t} & =\Delta \ln H_{t}^{\tau}+\Delta \ln \left(1-e r_{t}\right)-\Delta \ln \Phi_{t}+\Delta \hat{s}_{t}, \\
& =\hat{\gamma}_{H, t}+\hat{\gamma}_{e r, t}-\hat{\gamma}_{\Phi, t}+\Delta \hat{s}_{t} .
\end{aligned}
$$

Substituting equilibrium de-trended exchange rate (5) into the above depreciation rate solves the

\footnotetext{
${ }^{11}$ In particular, for an interest rate $r_{t},\left(1+\hat{r}_{t}\right)=\left(r_{t}-r^{*}\right) /\left(1+r^{*}\right)$.
} 
equilibrium depreciation rate as a linear function of the state variables:

$$
\begin{gathered}
\Delta \ln S_{t}=\psi(1-\kappa) \tilde{b}_{t-1}+\frac{(1-\kappa) \rho_{H}}{1-\kappa \rho_{H}} \hat{\gamma}_{H, t-1}+\frac{(1-\kappa) \rho_{e r}}{1-\kappa \rho_{e r}} \hat{\gamma}_{e r, t-1}-\frac{(1-\kappa) \rho_{\Phi}}{1-\kappa \rho_{\Phi}} \hat{\gamma}_{\Phi, t-1} \\
-\frac{(1-\kappa)\left(1-\rho_{h}\right)}{1-\kappa \rho_{h}} \hat{h}_{t-1}+\frac{\beta \eta-1}{1-\beta \eta(1-\lambda)} \epsilon_{A, t}+\frac{\beta \eta-1}{1-\beta \eta \rho_{y}} \epsilon_{y, t}-\frac{\beta \eta-1}{1-\beta \eta \rho_{q}} \epsilon_{q, t}+\frac{1-\kappa}{1-\kappa \rho_{h}} \epsilon_{h, t} \\
+\frac{1}{1-\kappa \rho_{H}} \epsilon_{H, t}+\frac{1}{1-\kappa \rho_{e r}} \epsilon_{e r, t}-\frac{1}{1-\kappa \rho_{\Phi}} \epsilon_{\Phi, t}+\frac{1-\kappa}{1-\kappa \rho_{H}} \epsilon_{\xi, t-2}+\frac{\kappa(1-\kappa)}{1-\kappa \rho_{H}} \epsilon_{\xi, t-1}+\frac{\kappa^{2}}{1-\kappa \rho_{H}} \epsilon_{\xi, t} \\
+\frac{1-\kappa}{1-\kappa \rho_{e r}} \epsilon_{\zeta, t-2}+\frac{\kappa(1-\kappa)}{1-\kappa \rho_{e r}} \epsilon_{\zeta, t-1}+\frac{\kappa^{2}}{1-\kappa \rho_{e r}} \epsilon_{\zeta, t} .
\end{gathered}
$$

Appendix C explains the full derivation of eq.(6).

The most important implication of equilibrium currency return (6) is that the logarithm of the exchange rate follows a Martingale difference sequence at the limit of $\kappa \rightarrow 1$ because

$$
\lim _{\kappa \rightarrow 1} E_{t} \Delta \ln S_{t+1}=0 .
$$

Therefore, in this paper, the exchange rate behaves like a random walk when the market discount factor approaches one along the equilibrium path of the two-country model. Eq. (6) exhibits no dependence of the currency return on past information in this case. Hence, the equilibrium random walk property of the exchange rate, as found in Engel and West (2005), Nason and Rogers (2008), and Kano (2014), is also preserved in this extended model. ${ }^{12}$

The intuition behind the equilibrium random walk property of the exchange rate is as follows. In this model, the nominal exchange rate is determined by the present discounted values of expected future economic fundamentals. As shown by Engel and West (2005), if economic fundamentals are $\mathrm{I}(1)$ and the market discount factor approaches one, a nominal exchange rate then follows a near random-walk process in equilibrium. This equilibrium random-walk property is attributable to the fact that only the Beveridge-Nelson trend components in the I(1) economic fundamentals are reflected in present-value calculation at the limit of the unit discount factor. Because the Beveridge-Nelson permanent component is a random walk, the current economic fundamentals lack the power to forecast future depreciation rates even along an equilibrium path.

The most crucial advantage of this two-country general equilibrium model over the past reduced-form type empirical exercises on random-walk exchange rates is that we can identify fundamental generators of a random-walk exchange rate as economically-meaningful structural shocks. Notice that at the limit of $\kappa \rightarrow 1$, the model also implies the subjective discount factor $\beta \rightarrow 1$ under

\footnotetext{
${ }^{12} \mathrm{~A}$ caveat of the above result is that in this model, $\kappa$ is given as a function of structural parameters $\beta, \gamma_{H}$, and $\gamma_{e r}: \kappa=\beta / \mu$. If $\mu>1$, as found in the postwar data on the adjusted monetary base growth rate in Japan and the United States, the admissible range of $\beta$ between zero and one implies that $\kappa$ is strictly less than one. In this paper, I assume that the limit of $\kappa \rightarrow 1$ is well approximated by the limit of $\beta \rightarrow 1$ because $\mu$ takes a value that is very close to one. Indeed, the sample mean of $\mu$ is 1.012 for Japan and 1.016 for the United States.
} 
$\mu$ approximately equal to one. In this limiting case, observe that the permanent monetary base shock $\epsilon_{H, t}$, the news shocks $\epsilon_{\xi, t}$ and $\epsilon_{\zeta, t}$, the excess reserve shock $\epsilon_{e r, t}$, and the money market shock $\epsilon_{\Phi, t}$ surely dominate the random walk exchange rate:

$$
\lim _{\kappa \rightarrow 1} \Delta \ln S_{t}=\frac{1}{1-\rho_{H}} \epsilon_{H, t}+\frac{1}{1-\rho_{H}} \epsilon_{\xi, t}+\frac{1}{1-\rho_{e r}} \epsilon_{e r, t}+\frac{1}{1-\rho_{e r}} \epsilon_{\zeta, t}-\frac{1}{1-\rho_{\Phi}} \epsilon_{\Phi, t} .
$$

Therefore, no transitory shock matters for the total variations in the random-walk exchange rate. This is because when $\kappa \rightarrow 1$, or equivalently, $r^{*} \rightarrow 0$, the interest rate differential becomes insensitive to the transitory money supply and the consumption differential. Hence, the exchange rate turns out to be neutral to any transitory monetary and real shocks. Moreover, eq.(7) clearly reveals that the model can generate the augmented Soros chart since shocks $\epsilon_{H, t}$ and $\epsilon_{e r, t}$ are the sole drivers of the adjusted monetary base differential $\ln \left(1-e r_{t}\right)+\ln H_{t}^{\tau}$. Finally, any deviations of the exchange rate from the augmented Soros chart should be explained by the money market shock $\epsilon_{\Phi, t}$ and two news shocks $\epsilon_{x i, t}$ and $\epsilon_{\zeta, t}$. Which structural shocks dominate the fluctuations of the Japanese yen/the U.S. dollar exchange rate is simply an empirical question. In the next section, we try to answer this empirical question by drawing a Bayesian posterior inference of the model.

\section{A Bayesian unobserved component approach}

\subsection{The restricted $U C$ model and posterior simulation strategy}

Let $\mathbf{X}_{t}$ denote an unobserved state vector defined as

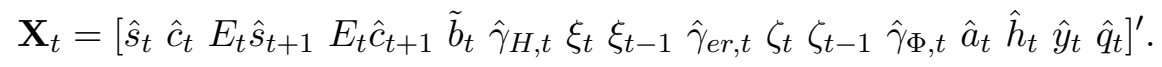

Furthermore, let $\epsilon_{t}$ and $\omega_{t}$ denote random vectors consisting of nine structural shocks and two rational expectations errors: $\epsilon_{t} \equiv\left[\epsilon_{H, t} \epsilon_{A, t} \epsilon_{h, t} \epsilon_{y, t} \epsilon_{q, t} \epsilon_{\Phi, t} \epsilon_{e r, t} \epsilon_{\xi, t} \epsilon_{\zeta, t}\right]^{\prime}$ and $\omega_{t} \equiv\left[\hat{s}_{t}-E_{t-1} \hat{s}_{t} \hat{c}_{t}-E_{t-1} \hat{c}_{t}\right]^{\prime}$, respectively. In particular, we presume that structural shock vector $\epsilon_{t}$ is normally distributed with a mean of zero and a diagonal variance-covariance matrix $\Sigma: \epsilon_{t} \sim$ i.i.d.N $(\mathbf{0}, \Sigma)$ with $\operatorname{diag}(\Sigma)=$ $\left[\begin{array}{llllllll}\sigma_{H}^{2} & \sigma_{A}^{2} & \sigma_{h}^{2} & \sigma_{y}^{2} & \sigma_{q}^{2} & \sigma_{\Phi}^{2} & \sigma_{e r}^{2} & \sigma_{\xi}^{2}, \sigma_{\zeta}^{2}\end{array}\right]^{\prime}$.

Accompanied by the stochastic processes of the exogenous forcing variables, the linear rational expectations model (4) then implies that

$$
\mathbf{B}_{0} \mathbf{X}_{t}=\mathbf{B}_{1} \mathbf{X}_{t-1}+\mathbf{A} \omega_{t}+\mathbf{R} \epsilon_{t}
$$

where $\mathbf{B}_{0}, \mathbf{B}_{1}, \mathbf{A}$, and $\mathbf{R}$ are the corresponding coefficient matrices. Applying Sims's (2001) QZ algorithm to the linear rational expectations model above yields a unique solution as the following stationary transition equation of the unobservable state vector:

$$
\mathbf{X}_{t}=\mathbf{F X}_{t-1}+\mathbf{Q} \epsilon_{t}
$$


where $\mathbf{F}$ and $\mathbf{Q}$ are confirmable coefficient matrices.

To construct this paper's UC model, we further expand unobservable state vector $\mathbf{X}_{t}$ by permanent monetary base differential $\ln H_{t}^{\tau}$, non-excess reserve ratio differential $\ln \left(1-e r_{t}\right)$, and money market shock differential $\ln \Phi_{t}$ to obtain expanded state vector $\mathbf{Z}_{t}: \mathbf{Z}_{t} \equiv\left[\mathbf{X}_{t}^{\prime} \ln H_{t}^{\tau} \ln (1-\right.$ $\left.\left.e r_{t}\right) \ln \Phi_{t}\right]^{\prime}$. The stochastic processes of $\ln H_{t}^{\tau}, \ln \left(1-e r_{t}\right)$, and $\ln \Phi_{t}$ and state transition (8) then imply the following non-stationary transition of $\mathbf{Z}_{t}$ :

$$
\mathbf{Z}_{t}=\mathbf{G Z}_{t-1}+\mathbf{D} \epsilon_{t}, \quad \epsilon_{t} \sim i . i . d . N(\mathbf{0}, \Sigma),
$$

where $\mathbf{G}$ and $\mathbf{D}$ are confirmable coefficient matrices.

In this paper, I explore time-series data on the logarithm of the consumption differential $\ln C_{t}$, the logarithm of the output differential $\ln Y_{t}$, the logarithm of the monetary base differential $\ln H_{t}$, the logarithm of the non-excess reserve ratio differential $\ln \left(1-e r_{t}\right)$, the interest rate differential $r_{t} \equiv r_{h, t}^{h}-r_{f, t}^{f}$, and the logarithm of the bilateral exchange rate $\ln S_{t}$. Let $\mathbf{Y}_{t}$ denote the information set that consists of these six time series: $\mathbf{Y}_{t} \equiv\left[\ln C_{t} \ln Y_{t} \ln H_{t} \ln \left(1-e r_{t}\right) r_{t} \ln S_{t}\right]^{\prime}$. It is then straightforward to show that information set $\mathbf{Y}_{t}$ is linearly related to unobservable state vector $\mathbf{Z}_{t}$ as

$$
\mathbf{Y}_{t}=\mathbf{H Z}_{t},
$$

where $\mathbf{H}$ is a confirmable coefficient matrix. Because we assume symmetric two-countries, the model has no implication on the constant term of information set $\mathbf{Y}_{t}$. The transition equation of the unobserved state (9) and the observation equation (10) jointly consist of a non-stationary state-space representation of the two-country model, which is the restricted UC model estimated in this paper. ${ }^{13}$

Given the data set $\mathbf{Y}^{T} \equiv\left\{\mathbf{Y}_{t}\right\}_{t=0}^{T}$, applying the Kalman filter to the UC model provides likelihood $\mathbf{L}\left(\mathbf{Y}^{T} \mid \theta\right)$, where $\theta$ is the structural parameter vector of the two-country model. Multiplying the likelihood by a prior probability of the structural parameters, $\mathbf{p}(\theta)$, is proportional to the corresponding posterior distribution $\mathbf{p}\left(\theta \mid \mathbf{Y}^{\mathbf{T}}\right) \propto \mathbf{p}(\theta) \mathbf{L}\left(\mathbf{Y}^{T} \mid \theta\right)$ through the Bayes law. The posterior distribution $\mathbf{p}\left(\theta \mid \mathbf{Y}^{T}\right)$ is simulated by the random-walk Metropolis-Hastings algorithm, as implemented by Kano (2014).

\subsection{Data and prior construction}

In this paper, we examine post-Plaza Accord quarterly data for Japan and the United States. The data span the period from Q1:1988 to Q4:2013. All the data included in information set $\mathbf{Y}^{T}$, except the nominal exchange rate, are seasonally adjusted annual rates. ${ }^{14}$ Because the

\footnotetext{
${ }^{13}$ The state-space form of the model, (9) and (10), decomposes the I(1) difference-stationary information set $\mathbf{Y}_{t}$ into permanent and transitory components exploiting the theoretical restrictions provided by the two-country model. Recursion of the Kalman filter for a non-stationary state-space model is explained in detail by Hamilton (1994).

${ }^{14}$ Appendix D provides a detailed description of the source and construction of the data examined in this paper.
} 
model has no implication of the constant term of the information set due to our symmetric twocountry assumption, we subtract the corresponding sample means from all the data to construct the information set before estimation.

Table 1 reports the prior distributions of the structural parameters of the two-country model, $\mathbf{p}(\theta)$. We follow Kano (2014) to construct the prior distributions. In particular, we elicit a uniform prior distribution of $\kappa$ and let the data tell the posterior position of $\kappa$ given the identification of the restricted UC model. In so doing, on the one hand, the prior distribution of mean gross monetary growth rate $\mu$ is intended to tightly cover its sample counterparts in both countries through the Gamma distribution with a mean of 1.015 and standard deviation of 0.005 . On the other hand, the prior distribution of subjective discount factor $\beta$ is uniformly distributed between zero and one. As a result, the prior distribution of market discount factor $\kappa$ is well approximated as the uniform distribution spread over the support of the unit interval.

\subsection{Results}

Table 2 reports the posterior distributions of the structural parameters. The second, third, and fourth columns correspond to the means, the standard deviations, and the $95 \%$ Bayesian highest probability density (HPD) intervals of the the posterior distributions, respectively. An outstanding observation in the table should be found in the posterior distribution of market discount factor $\kappa$. The posterior mean of $\kappa$ is 0.961 , which is very close to the posterior means of the market discount factor around 0.960 observed by Nason and Rogers (2008), Sarno and Sojli (2005), Balke et al. (2013). ${ }^{15}$ This empirically relevant inference on the market discount factor does not depend on any prior information because of the uniform prior distribution of $\kappa$. The reasonable size of the discount factor is identified by the model's restrictions imposed on the data.

The estimated market discount factor close to one, indeed, results in a good fit of the model to the near random-walk Japanese yen/U.S. dollar rate. According to the model's theoretical implication (7), the currency return should be well approximated by $\epsilon_{H, t}, \epsilon_{\xi, t}, \epsilon_{e r, t}, \epsilon_{\zeta, t}$, and $\epsilon_{\Phi, t}$ under the discount factor close to one. Figure 3 plots the currency return in the data (the solid black line) and the sum of the smoothed inferences of $\epsilon_{H, t}, \epsilon_{\xi, t}, \epsilon_{e r, t}, \epsilon_{\zeta, t}$, and $\epsilon_{\Phi, t}$ through the Kalman smoother (the dashed blue line). Observe that the bumpy depreciation rate of the Japanese yen against the U.S. dollar is almost perfectly tracked by the sum of the smoothed inferences of these permanent shocks. Therefore, our model successfully explains the near random-walk behavior of the Japanese yen/U.S. dollar rate.

Is the model successful in mimicking the two versions the Soros chart? Figures 4(a) and

\footnotetext{
${ }^{15}$ In contrast, Kano (2014) conducts the similar posterior simulation of the two-country general equilibrium model with the post-Bretton Woods sample of Canada and the United State and found a much smaller posterior mean of $\kappa$ of 0.525 .
} 
(b) just add the model's smoothed inferences of the two versions of the Soros chart to Figures 1(a) and (b). More precisely, in Figure 4(a), the smoothed inference of the differential in the permanent component of the monetary base between the two countries, $\ln H_{t}^{\tau}$, is plotted as the dotted dashed red line, while in Figure 4(b) the sum of the smoothed inferences of the differentials in the permanent component of the monetary bases and the non-excess reserve component, $\ln H_{t}^{\tau}+\ln \left(1-e r_{t}\right)$, is displayed as the dotted dashed red line. Notice that the model's smoothed inferences on the cross-country differentials in the permanent components of the non-augmented and augmented monetary base almost perfectly replicate both the failure of the first Soros chart and the success of the second simultaneously. Hence, in our model, the augmented Soros chart is identified as a common stochastic trend that explains the slow-moving low-frequency component of the post-Plaza Accord Japanese yen/U.S. dollar exchange rate. ${ }^{16}$

Given the augmented Solos chart as the slow-moving stochastic trend of the Japanese yen/U.S. dollar, what shocks explain the sharp transitory deviations of the Japanese yen/U.S. dollar exchange rate from the Soros chart? Table 3 reports the forecast error variance decompositions (FEVDs) of the currency return, the growth rate of the consumption differential, and the interest rate differential into the nine structural shocks at selected forecast horizons $(0,1,2,3,4$, 8, 12, and 40 quarters ahead). ${ }^{17}$ Table 3(a) clearly shows that permanent monetary base shock $\epsilon_{H, t}$, money market shock $\epsilon_{\Phi, t}$, and non-excess reserve shock $\epsilon_{e r, t}$ dominate the fluctuations of the currency return from the impact period to the 10 years ahead.

Recall that the money market shock is estimated as a mixture of the money demand shock and the money multiplier. To draw an inference of the role of the money demand shock from the estimated money market shock, we calculate the money multiplier differential $\Psi_{t}$ from the actual data, dividing the two-country M2 differential $M_{t}$ by the augmented monetary base differential $\left(1-e r_{t}\right) H_{t}$. Figure 5 then reports the historical decomposition of the currency return into three structural shocks: permanent augmented monetary base shock $\ln \left(1-e r_{t}\right)+\ln H_{t}^{\tau}$ (the left window), money demand shock $\Gamma_{t}$ (the middle center window), and money multiplier $\Psi_{t}$ (the right window). Specifically, each window plots the actual currency return as the solid black line and the smoothed inference of the corresponding structural shock as the dashed blue line. Observe that the identified money demand shock traces the transitory movement of the exchange rate, i.e., the currency return, very tightly. Hence, the money demand shock is identified as the main generator of the transitory component of the Japanese yen/U.S. dollar rate.

\footnotetext{
${ }^{16}$ It is worth noting that Figures 4(a) and (b) plot only the permanent component of the monetary base differential from the Kalman smoothed inference of the model using the actual data of the monetary base differential. Hence, it is not obvious a priori that we can obtain a perfect replication of the Soros chart. The result depends on the estimation of the transitory component of the monetary base differential, which also is affected by the other cross-equation restrictions of the model imposed on the data of the monetary base differential as well as the interest rate differential. See Kano (2014) for the whole derivation of the cross-equation restrictions of the model in more detail.

${ }^{17}$ The estimated FEVDs are evaluated at the posterior means of the structural parameters.
} 
Our model also is able to describe the disconnection of the Japanese yen/U.S. dollar exchange rate with real economic variables. The FEVDs of the currency return reported in Table 3 (a) reveal the fact that none of real shocks, i.e., the TFP shock $\epsilon_{A, t}$, the transitory output shock $\epsilon_{y, t}$, and the PPP deviation shock $\epsilon_{q, t}$ plays a significant role in driving the currency return. Table $3(\mathrm{~b})$, on the other hand, conveys the FEVDs of the consumption differential growth rate into the structural shocks. It is clear that TFP shock $\epsilon_{A, t}$ and PPP deviation shock $\epsilon_{q, t}$ are the main drivers of the consumption differential growth. ${ }^{18}$ Therefore, our model replicates the disconnection of the exchange rate from the real variables in the data plausibly.

Table 3(c) reports the FEVDs of the interest rate differential into the structural shocks. An outstanding inference the FEVDs draw is that the news shock to the permanent component of the augmented monetary base, $\epsilon_{\xi, t}$ and $\epsilon_{\zeta, t}$, affect the interest rate differential instantaneously. This result implies that the interest rate differential is determined by the forward-looking anticipated information about the monetary base differential in near future. The tight linkage of the interest rate differential with the slow-moving component of the currency return in the data should be generated by the current news about future permanent shifts in the relative size of the monetary base between the two countries.

\subsection{What depreciates the Japanese yen under the Abenomics?}

As shown in Figure 5, our paper identifies the dominant driver of the currency return, i.e., the short-run transitory component of the Japanese yen/U.S. dollar exchange rate, as the twocountry differential in the money demand shock, $\Gamma_{t}$. Because there is no theoretical restriction the model imposes on this structural shock and the data, the money demand shock indeed acts as a free parameter in our posterior simulation of the restricted unobserved component model. Hence, it is still too ambitious to interpret $\Gamma_{t}$ as the cross-country differential in the money demand shock

\footnotetext{
${ }^{18}$ This independence of the consumption growth rate from the monetary disturbances stems from the monetary super-neutrality with the money-in-utility lifetime utility function and the model's absence from price stickiness. Indeed, the model derive the log-linear approximated saddle path of the consumption differential:

$$
\ln C_{t}=\frac{1-\beta \eta}{\beta p_{h}^{*} y^{*}} \tilde{b}_{t-1}+\frac{1-\beta \eta}{1-\beta \eta(1-\lambda)} \hat{a}_{t}+\frac{\beta \eta\left(1-\rho_{q}\right)}{1-\beta \eta \rho_{q}} \hat{q}_{t}+\frac{1-\beta \eta}{1-\beta \eta \rho_{y}} \hat{y}_{t} .
$$

Then as shown by Kano (2014), at the limit of $\kappa \rightarrow 1$, the consumption differential approaches the PPP deviation

$$
\lim _{\kappa \rightarrow 1} \ln C_{t}=\ln q_{t}
$$

Therefore, Backus and Smith's (1993) puzzle holds at the limit of the unit discount factor: the consumption differential is correlated perfectly with the real exchange rate. The reason behind the Backus and Smith puzzle is that any country specific TFP shock becomes common across the two countries in the long run through cointegration, and at the limit of the unit discount factor the permanent income of the two countries responds similarly to such a country-specific TFP shock. Hence only the driver of the consumption differential is an instantaneous change in the relative price of the consumption basket, i.e., the real exchange rate. See Kano (2014) for the detailed discussion for the Backus and Smith puzzle.
} 
literally.

Importantly, the identified cross-country differential in the money demand shock, $\Gamma_{t}$, backs the sharp depreciation of the Japanese yen against the U.S. dollar that occurred after Q4:2012 when most market participants expected surely the "first arrow" of the Abenomics. The paper's absence from a shaper structural identification of the money demand shock makes it difficult to understand any possible effect of the Abenomics on the sudden depreciation of the Japanese Japanese yen against the U.S. dollar between Q4:2012 and Q4:2013 within our model. A part of the reason behind the failure of our model in uncovering the major source of the sharp deprecation of the Japanese yen might be purely empirical: there has been only a short sample with four quarters since the beginning of the Abenomics in our empirical exercise. It, however, is more desirable to find another theoretical restriction to extract pure money demand shocks from the data by augmenting our model further. From this view point, the most possible way might be to include a more realistic monetary policy framework with an interest rate setting rule, i.e., the Taylor rule. On one hand, we can expect that a correctly specified interest rate setting rule might lead to a better structural interpretation of the money demand shocks identified by this paper. On the other hand, once we recognize that the BOJ and the Fed are still adopting the zero interest rate policies, we suspect the short-term interest rate differential to reveal no additional information about the sharp depreciation of the Japanese yen against the U.S. dollar under the Abenomics.

It is the limitation of the paper's investigation to take into consideration only the short-term interest rate differential especially under the unconventional monetary policies conducted by the BOJ and the Fed because their policy channels are intended to affect longer-term interest rates through the zero interest rate policies, the QEs, and the forward guidance policies. Indeed, there is evidence that longer-term interest rate differentials between Japan and the United States are tightly correlated with the Japanese yen/ U.S. dollar exchange rate after the Abenomics. Figure 6 plots the monthly data of the term structure of the Japan and the U.S. interest rate differential between January 2012 and December 2014. In particular, the minus of the logarithm of the yen/U.S. dollar rate is depicted as the solid black line, the one-year government bond yield differential between Japan and the United States the dotted gray line, the two-year differential the dotted black line, the five-year differential the dashed black line, and the ten-year differential the dashed gray line, respectively. Observe that the Japanese yen/U.S. dollar rate co-moves much tightly with the longerterm yield differentials with the five- and ten-year maturities rather than the shorter-term yield differentials with the one- and two-year maturities. ${ }^{19}$ This fact is quite suggestive that the paper's identified money demand shock differential $\Gamma_{t}$ uncover any effects of the unconventional monetary policies of the BOJ and the Fed on the longer-term interest rate differentials. Bridging theoretical

\footnotetext{
${ }^{19}$ The unconditional correlation coefficients of the exchange rate are estimated to be -0.040 with one-year yield differential, -0.754 with two-year differential, -0.867 with five-year differential, and -0.853 with ten-year differential, respectively.
} 
and empirical gaps between the identified money demand shock and the term structure of the interest rate differential is a challenging task we leave as important future research agenda.

\section{Conclusion}

In this paper, we try to figure out the data characteristics of the post-Plaza accord sample of the Japanese yen/the U.S. dollar nominal exchange rate. The simple two-country incompletemarket model this paper proposes fits to these sample moments well. In particular, the near Martingale difference property of the depreciation rate of the Japanese yen against the U.S. dollar,

which has resisted many past attempts to explain within equilibrium models, can be replicated by our canonical two-country general equilibrium model under empirically plausible parameterization. The model implies that once we recognize the nonstationarity of the augmented monetary base differential, the market discount factor close to one makes it fully understandable that the augmented Soros chart acts as a common stochastic trend of the Japanese yen/the U.S. dollar rate. We hope that our exercise sheds some new light on the positive and normative studies of the Japanese yen/the U.S. dollar exchange rate through structural general equilibrium frameworks.

\section{Appendix A. Stochastically de-trended system}

The stochastically de-trended versions of the home country's FONCs are of the budget constraint

$$
p_{h, t} c_{h, t}+b_{h, t}^{h}+s_{t} b_{h, t}^{f}=\left(1+r_{h, t-1}^{h}\right) b_{h, t-1}^{h} \gamma_{\Phi, t}^{h} /\left(\gamma_{e r, t}^{h} \gamma_{H, t}^{h}\right)+\left(1+r_{h, t-1}^{f}\right) s_{t} b_{h, t-1}^{f} \gamma_{\Phi, t}^{f} /\left(\gamma_{e r, t}^{f} \gamma_{H, t}^{f}\right)+p_{h, t} y_{h, t},
$$

of the Euler equation

$$
\frac{1}{p_{h, t} c_{h, t}}=\beta\left(1+r_{h, t}^{h}\right) E_{t}\left(\frac{\gamma_{\Phi, t+1}^{h}}{\gamma_{e r, t+1}^{h} \gamma_{H, t+1}^{h} p_{h, t+1} c_{h, t+1}}\right)
$$

of the UIP condition

$$
s_{t}\left(1+r_{h, t}^{h}\right) E_{t}\left(\frac{\gamma_{\Phi, t+1}^{h}}{p_{h, t+1} c_{h, t+1} \gamma_{e r, t+1}^{h} \gamma_{H, t+1}^{h}}\right)=\left(1+r_{h, t}^{f}\right) E_{t}\left(\frac{s_{t+1} \gamma_{\Phi, t+1}^{f}}{p_{h, t+1} c_{h, t+1} \gamma_{e r, t+1}^{f} \gamma_{H, t+1}^{f}}\right),
$$

of the money demand function

$$
\frac{h_{h, t}}{p_{h, t}}=c_{h, t}\left(\frac{1+r_{h, t}^{h}}{r_{h, t}^{h}}\right)
$$

the risk premium

$$
r_{h, t}^{h}=r_{w, t}^{h}\left[1+\psi\left\{\exp \left(-b_{h, t}^{h}+\bar{d}\right)-1\right\}\right]
$$

and

$$
r_{h, t}^{f}=r_{w, t}^{f}\left[1+\psi\left\{\exp \left(-b_{h, t}^{f}+\bar{d}\right)-1\right\}\right] .
$$


Similarly, the stochastically de-trended versions of the FONCs of the foreign country are of the budget constraint

$$
\begin{aligned}
q_{t} p_{h, t} c_{f, t}-a_{t} s_{t} b_{h, t}^{f}-a_{t} b_{h, t}^{h}=-\left(1+r_{w, t-1}^{f}\right) a_{t} s_{t} b_{h, t-1}^{f} \gamma_{\Phi, t}^{f} /\left(\gamma_{e r, t}^{f} \gamma_{H, t}^{f}\right) \\
-\left(1+r_{w, t-1}^{h}\right) a_{t} b_{h, t-1}^{h} \gamma_{\Phi, t}^{h} /\left(\gamma_{e r, t}^{h} \gamma_{H, t}^{h}\right)+q_{t} p_{h, t} y_{f, t},
\end{aligned}
$$

of the Euler equation

$$
\frac{a_{t} s_{t}}{q_{t} p_{h, t} c_{f, t}}=\beta\left(1+r_{w, t}^{f}\right) E_{t} \frac{a_{t+1} s_{t+1} \gamma_{\Phi, t+1}^{f}}{\gamma_{e r, t+1}^{f} \gamma_{H, t+1}^{f} q_{t+1} p_{h, t+1} c_{f, t+1}},
$$

of the UIP condition

$$
\left(1+r_{w, t}^{h}\right) E_{t}\left(\frac{a_{t+1} \gamma_{\Phi, t+1}^{h}}{q_{t+1} p_{h, t+1} c_{f, t+1} \gamma_{e r, t+1}^{h} \gamma_{H, t+1}^{h}}\right)=\frac{\left(1+r_{w, t}^{f}\right)}{s_{t}} E_{t}\left(\frac{a_{t+1} s_{t+1} \gamma_{\Phi, t+1}^{f}}{q_{t+1} p_{h, t+1} c_{f, t+1} \gamma_{e r, t+1}^{f} \gamma_{H, t+1}^{f}}\right),
$$

and of the money demand function

$$
\frac{a_{t} s_{t} h_{f, t}}{q_{t} p_{h, t}}=c_{f, t}\left(\frac{1+r_{w, t}^{f}}{r_{w, t}^{f}}\right)
$$

If the TFP differential $a_{t}$ is I(1) as assumed in NR, the above system of stochastic difference equations becomes nonstationary through the home and foreign budget constraints and there is no deterministic steady state to converge. Notice that neither the cross-country permanent monetary base differential $\ln \left(1-e r_{h, t}\right) H_{h, t}^{\tau} /\left(1-e r_{f, t}\right) H_{f, t}^{\tau}$ nor the cross-country money market shock differential $\ln \Phi_{h, t} / \Phi_{f, t}$ appears in the stochastically de-trended system of the FONCs. In contrast to the TFP differential $a_{t}$, the I(1) properties of $\ln \left(1-e r_{h, t}\right) H_{h, t}^{\tau} /\left(1-e r_{f, t}\right) H_{f, t}^{\tau}$ and $\ln \Phi_{h, t} / \Phi_{f, t}$ do not matter for the closing of the model. This might be an obvious result of the model's property that the super-neutrality of money holds in the money-in-utility model: Money growth does not matter for the deterministic steady state. Notice that at the deterministic steady state, the TFP differential $a^{*}$ is one. Because of the stationarity of the system of equations, the deterministic steady state is characterized by constants $c_{h}^{*}, c_{f}^{*}, p_{h}^{*}, s^{*}, b_{h}^{h *}, b_{h}^{f *}, r_{h}^{h *}, r_{h}^{f *}, r_{w}^{h *}$, and $r_{w}^{f *}$ that satisfy

$$
\begin{aligned}
b_{h}^{h *} & =b_{h}^{f *}=\bar{d}, \\
r^{*} & \equiv r_{h}^{h *}=r_{f}^{f *}=r_{w}^{h *}=r_{w}^{f *}=\mu / \beta-1, \\
s^{*} & =\frac{y_{f}(\mu)^{-1} r^{*}+\left(y_{h}+y_{f}\right)\left(1-\beta^{-1}\right) \bar{d}}{y_{h}(\mu)^{-1} r^{*}-\left(y_{h}+y_{f}\right)\left(1-\beta^{-1}\right) \bar{d}} \\
p_{h}^{*} y_{h} & =\left(1-\beta^{-1}\right)\left(1+s^{*}\right) \bar{d}+(\mu)^{-1} r^{*}, \\
p_{h}^{*} c_{h}^{*} & =(\mu)^{-1} r^{*} \\
c_{f}^{*} & =s^{*} c_{h}^{*} .
\end{aligned}
$$

Appendix B. The log-linear approximation of the stochastically de-trended system and the derivation of the saddle path (5) 
The log-linear approximation of the stochastically de-trended home budget constraint is

$$
\begin{aligned}
& p_{h}^{*}\left(c_{h}^{*}-y_{h}\right) \hat{p}_{h, t}+p_{h}^{*} c_{h}^{*} \hat{c}_{h, t}-p_{h}^{*} y_{h} \hat{y}_{h, t}+\tilde{b}_{h, t}^{h}+\bar{d}\left(1-\beta^{-1}\right) s^{*} \hat{s}_{t}+s^{*} \tilde{b}_{h, t}^{f} \\
& =\beta^{-1} \bar{d}\left[\left(1+\hat{r}_{h, t-1}^{h}\right)-\hat{\gamma}_{H, t}^{h}-\hat{\gamma}_{e r, t}^{h}+\hat{\gamma}_{\Phi, t}^{h}\right]+s^{*} \beta^{-1} \bar{d}\left[\left(1+\hat{r}_{h, t-1}^{f}\right)-\hat{\gamma}_{H, t}^{f}-\hat{\gamma}_{e r, t}^{f}+\hat{\gamma}_{\Phi, t}^{f}\right] \\
& +\beta^{-1} \tilde{b}_{h, t-1}^{h}+s^{*} \beta^{-1} \tilde{b}_{h, t-1}^{f} \text {; }
\end{aligned}
$$

that of the home Euler equation is

$$
\hat{p}_{h, t}+\hat{c}_{h, t}+\left(1+\hat{r}_{h, t}^{h}\right)=E_{t}\left(\hat{p}_{h, t+1}+\hat{c}_{h, t+1}+\hat{\gamma}_{H, t+1}^{h}+\hat{\gamma}_{e r, t+1}^{h}-\hat{\gamma}_{\Phi, t+1}^{h}\right)
$$

that of the home UIP condition is

$$
E_{t} \hat{s}_{t+1}-\hat{s}_{t}=\left(1+\hat{r}_{h, t}^{h}\right)-\left(1+\hat{r}_{h, t}^{f}\right)+E_{t}\left(\hat{\gamma}_{\Phi, t+1}^{h}-\hat{\gamma}_{\Phi, t+1}^{f}-\hat{\gamma}_{H, t+1}^{h}+\hat{\gamma}_{H, t+1}^{f}-\hat{\gamma}_{e r, t+1}^{h}+\hat{\gamma}_{e r, t+1}^{f}\right)
$$

and that of the home money demand function is

$$
\hat{p}_{h, t}+\hat{c}_{h, t}-\hat{h}_{h, t}=\frac{1}{r^{*}}\left(1+\hat{r}_{h, t}^{h}\right) .
$$

The foreign country's counterparts are the log-linear approximation of the stochastically de-trended foreign budget constraint

$$
\begin{array}{r}
p_{h}^{*}\left(c_{f}^{*}-y_{f}\right)\left(\hat{p}_{h, t}+\hat{q}_{t}-\hat{a}_{t}-\hat{s}_{t}\right)+p_{h}^{*} c_{f}^{*} \hat{c}_{f, t}-p_{h}^{*} y_{f} \hat{y}_{f, t}-\tilde{b}_{h, t}^{h}-\bar{d}\left(1-\beta^{-1}\right) s^{*} \hat{s}_{t}-s^{*} \tilde{b}_{h, t}^{f} \\
=-\beta^{-1} \bar{d}\left[\left(1+\hat{r}_{w, t-1}^{h}\right)-\hat{\gamma}_{H, t}^{h}-\hat{\gamma}_{e r, t}^{h}+\hat{\gamma}_{\Phi, t}^{h}\right]-s^{*} \beta^{-1} \bar{d}\left[\left(1+\hat{r}_{w, t-1}^{f}\right)-\hat{\gamma}_{H, t}^{f}-\hat{\gamma}_{e r, t}^{f}+\hat{\gamma}_{\Phi, t}^{f}\right] \\
-\beta^{-1} \tilde{b}_{h, t-1}^{h}-s^{*} \beta^{-1} \tilde{b}_{h, t-1}^{f}
\end{array} ;
$$

that of the foreign Euler equation

$$
\hat{a}_{t}+\hat{s}_{t}-\hat{p}_{h, t}-\hat{c}_{f, t}-\hat{q}_{t}-\left(1+\hat{r}_{w, t}^{f}\right)=E_{t}\left(\hat{a}_{t+1}+\hat{s}_{t+1}-\hat{p}_{h, t+1}-\hat{c}_{f, t+1}-\hat{q}_{t+1}-\hat{\gamma}_{H, t+1}^{f}-\hat{\gamma}_{e r, t+1}^{f}+\hat{\gamma}_{\Phi, t+1}^{f}\right)
$$

that of the foreign UIP condition

$$
E_{t} \hat{s}_{t+1}-\hat{s}_{t}=\left(1+\hat{r}_{w, t}^{h}\right)-\left(1+\hat{r}_{w, t}^{f}\right)+E_{t}\left(\hat{\gamma}_{\Phi, t+1}^{h}-\hat{\gamma}_{\Phi, t+1}^{f}-\hat{\gamma}_{H, t+1}^{h}+\hat{\gamma}_{H, t+1}^{f}-\hat{\gamma}_{e r, t+1}^{h}+\hat{\gamma}_{e r, t+1}^{f}\right)
$$

and that of the home money demand function

$$
\hat{a}_{t}+\hat{s}_{t}+\hat{h}_{f, t}-\hat{p}_{h, t}-\hat{c}_{f, t}-\hat{q}_{t}=-\frac{1}{r^{*}}\left(1+\hat{r}_{w, t}^{f}\right) .
$$

The log-linear approximations of the home country's interest rates are

$$
\left(1+\hat{r}_{h, t}^{h}\right)=\left(1+\hat{r}_{w, t}^{h}\right)-\psi(1-\kappa) \tilde{b}_{h, t}^{h}, \quad \text { and } \quad\left(1+\hat{r}_{h, t}^{f}\right)=\left(1+\hat{r}_{w, t}^{f}\right)-\psi(1-\kappa) \tilde{b}_{h, t}^{f} .
$$

Notice that the home interest rates (B.9) redefine the home UIP condition (B.3) as

$$
\begin{aligned}
E_{t} \hat{s}_{t+1}-\hat{s}_{t}=\left(1+\hat{r}_{w, t}^{h}\right)-\left(1+\hat{r}_{w, t}^{f}\right)-\psi(1-\kappa)\left(\tilde{b}_{h, t}^{h}-\tilde{b}_{h, t}^{f}\right) & \\
& +E_{t}\left(\hat{\gamma}_{\Phi, t+1}^{h}-\hat{\gamma}_{\Phi, t+1}^{f}-\hat{\gamma}_{H, t+1}^{h}+\hat{\gamma}_{H, t+1}^{f}-\hat{\gamma}_{e r, t+1}^{h}+\hat{\gamma}_{e r, t+1}^{f}\right) .
\end{aligned}
$$

Comparing the above home UIP condition with the foreign UIP condition (B.7) implies that the home and foreign bonds are perfectly substitutable along the equilibrium path. Hence, the equilibrium condition $\tilde{b}_{t} \equiv \tilde{b}_{h, t}^{h}=\tilde{b}_{h, t}^{f}$ holds. 
The saddle path of the exchange rate in this model is derived as follows. Set the parameter $\bar{d}$ to zero and assume that the transitory output components of the two countries, $y_{h}$ and $y_{f}$, are equal to $y$. We then combine the log-linearized Euler equations of the home and foreign countries, (B.2) and (B.6), with those of the home country's interest rates (B.9) to yield the first-order expectational difference equation of $\hat{a}_{t}+\hat{s}_{t}+\hat{c}_{t}$ :

$$
\hat{a}_{t}+\hat{s}_{t}+\hat{c}_{t}-\hat{q}_{t}=\kappa E_{t}\left(\hat{a}_{t+1}+\hat{s}_{t+1}+\hat{c}_{t+1}-\hat{q}_{t+1}\right)+\kappa E_{t}\left(\hat{\gamma}_{H, t+1}+\hat{\gamma}_{e r, t+1}-\hat{\gamma}_{\Phi, t+1}\right)+(1-\kappa) \hat{h}_{t} .
$$

Since $\kappa$ takes a value between zero and one, the above expectational difference equation has a forward solution of

$$
\begin{aligned}
\hat{a}_{t}+\hat{s}_{t}+\hat{c}_{t}-\hat{q}_{t}=\frac{\kappa \rho_{H}}{1-\kappa \rho_{H}} \hat{\gamma}_{H, t}+\frac{\kappa}{1-\kappa \rho_{H}} \xi_{t-1} & +\frac{\kappa^{2}}{1-\kappa \rho_{H}} \xi_{t}+\frac{\kappa \rho_{e r}}{1-\kappa \rho_{e r}} \hat{\gamma}_{e r, t} \\
& +\frac{\kappa}{1-\kappa \rho_{e r}} \zeta_{t-1}+\frac{\kappa^{2}}{1-\kappa \rho_{e r}} \zeta_{t}-\frac{\kappa \rho_{\Phi}}{1-\kappa \rho_{\Phi}} \hat{\gamma}_{\Phi, t}+\frac{1-\kappa}{1-\kappa \rho_{h}} \hat{h}_{t}
\end{aligned}
$$

under a suitable transversality condition. By exploiting this forward solution and the stochastic processes of both countries' TFPs, we rewrite the foreign UIP condition (B.7) as

$$
\begin{aligned}
E_{t} \hat{s}_{t+1}-\hat{s}_{t}=\psi(1-\kappa) \tilde{b}_{t} & -\frac{\kappa \rho_{H}\left(1-\rho_{H}\right)}{1-\kappa \rho_{H}} \hat{\gamma}_{H, t}-\frac{\kappa\left(1-\rho_{H}\right)}{1-\kappa \rho_{H}} \xi_{t-1}+\frac{\kappa(1-\kappa)}{1-\kappa \rho_{H}} \xi_{t}-\frac{\kappa \rho_{e r}\left(1-\rho_{e r}\right)}{1-\kappa \rho_{e r}} \hat{\gamma}_{e r, t} \\
& -\frac{\kappa\left(1-\rho_{e r}\right)}{1-\kappa \rho_{e r}} \zeta_{t-1}+\frac{\kappa(1-\kappa)}{1-\kappa \rho_{e r}} \zeta_{t}+\frac{\kappa \rho_{\Phi}\left(1-\rho_{\Phi}\right)}{1-\kappa \rho_{\Phi}} \hat{\gamma}_{\Phi, t}-\frac{(1-\kappa)\left(1-\rho_{h}\right)}{1-\kappa \rho_{h}} \hat{h}_{t},
\end{aligned}
$$

Furthermore, taking a difference between the log-linearized budget constraints of the home and foreign countries, (B.1) and (B.5), we find the law of motion of the international bond holdings

$$
\begin{aligned}
\tilde{b}_{t}=\beta^{-1} \tilde{b}_{t-1}+p_{h}^{*} y^{*}\left(\hat{a}_{t}+\hat{s}_{t}-\hat{q}_{t}+\hat{y}_{t}\right)-\frac{p_{h}^{*} y^{*} \kappa \rho_{H}}{1-\kappa \rho_{H}} \hat{\gamma}_{H, t}-\frac{p_{h}^{*} y^{*} \kappa}{1-\kappa \rho_{H}} \xi_{t-1}-\frac{p_{h}^{*} y^{*} \kappa^{2}}{1-\kappa \rho_{H}} \xi_{t} \\
-\frac{p_{h}^{*} y^{*} \kappa \rho_{e r}}{1-\kappa \rho_{e r}} \hat{\gamma}_{e r, t}-\frac{p_{h}^{*} y^{*} \kappa}{1-\kappa \rho_{e r}} \zeta_{t-1}-\frac{p_{h}^{*} y^{*} \kappa^{2}}{1-\kappa \rho_{e r}} \zeta_{t}+\frac{p_{h}^{*} y^{*} \kappa \rho_{\Phi}}{1-\kappa \rho_{\Phi}} \hat{\gamma}_{\Phi, t}-\frac{p_{h}^{*} y^{*}(1-\kappa)}{1-\kappa \rho_{h}} \hat{h}_{t},
\end{aligned}
$$

where $y^{*}=y / 4$ and $\hat{y}_{t} \equiv \hat{y}_{h, t}-\hat{y}_{f, t}$.

Combining equation (B.10) with equation (B.11) then yields the following second-order expectational difference equation with respect to international bond holdings:

$$
E_{t} \tilde{b}_{t+1}-\left[1+\beta^{-1}+p_{h}^{*} y^{*} \psi(1-\kappa)\right] \tilde{b}_{t}+\beta^{-1} \tilde{b}_{t-1}=-p_{h}^{*} y^{*} \lambda \hat{a}_{t}+p_{h}^{*} y^{*}\left(1-\rho_{q}\right) \hat{q}_{t}-p_{h}^{*} y^{*}\left(1-\rho_{y}\right) \hat{y}_{t}
$$

It is straightforward to show that equation (B.12) has two roots, one of which is greater than one and the other of which is less than one. ${ }^{20}$ Without losing generality, let $\eta$ denote the root that is less than one. Root $\eta$ satisfies $(\beta \eta-1)(\eta-1)=\beta \eta p_{h}^{*} y^{*} \psi(1-\kappa)$. Solving equation (B.12) by forward iterations then shows that the equilibrium international bond holdings level is determined by the following cross-equation restriction (CER):

$$
\begin{aligned}
\tilde{b}_{t} & =\eta \tilde{b}_{t-1}+\beta \eta \lambda p_{h}^{*} y^{*} \sum_{j=0}^{\infty}(\beta \eta)^{j} E_{t} \hat{a}_{t+j}+\beta \eta p_{h}^{*} y^{*}\left(1-\rho_{y}\right) \sum_{j=0}^{\infty}(\beta \eta)^{j} E_{t} \hat{y}_{t+j}-\beta \eta p_{h}^{*} y^{*}\left(1-\rho_{q}\right) \sum_{j=0}^{\infty}(\beta \eta)^{j} E_{t} \hat{q}_{t+j}, \\
& =\eta \tilde{b}_{t-1}+\frac{\beta \eta \lambda p_{h}^{*} y^{*}}{1-\beta \eta(1-\lambda)} \hat{a}_{t}+\frac{\beta \eta p_{h}^{*} y^{*}\left(1-\rho_{y}\right)}{1-\beta \eta \rho_{y}} \hat{y}_{t}-\frac{\beta \eta p_{h}^{*} y^{*}\left(1-\rho_{q}\right)}{1-\beta \eta \rho_{q}} \hat{q}_{t} .
\end{aligned}
$$

\footnotetext{
${ }^{20}$ To characterize the roots of the second-order expectational difference equation, see, for example, Sargent (1987).
} 
Substituting equation (B.13) back into equation (B.11) provides the CER for the exchange rate (5):

$$
\begin{aligned}
\hat{s}_{t}=\frac{\beta \eta-1}{\beta p_{h}^{*} y^{*}} \tilde{b}_{t-1} & +\frac{\beta \eta-1}{1-\beta \eta(1-\lambda)} \hat{a}_{t}+\frac{1-\kappa}{1-\kappa \rho_{h}} \hat{h}_{t}+\frac{\beta \eta-1}{1-\beta \eta \rho_{y}} \hat{y}_{t}-\frac{\beta \eta-1}{1-\beta \eta \rho_{q}} \hat{q}_{t}+\frac{\kappa \rho_{H}}{1-\kappa \rho_{H}} \hat{\gamma}_{H, t} \\
+ & \frac{\kappa}{1-\kappa \rho_{H}} \xi_{t-1}+\frac{\kappa^{2}}{1-\kappa \rho_{H}} \xi_{t}+\frac{\kappa \rho_{e r}}{1-\kappa \rho_{e r}} \hat{\gamma}_{e r, t}+\frac{\kappa}{1-\kappa \rho_{e r}} \zeta_{t-1}+\frac{\kappa^{2}}{1-\kappa \rho_{e r}} \zeta_{t}-\frac{\kappa \rho_{\Phi}}{1-\kappa \rho_{\Phi}} \hat{\gamma}_{\Phi, t}
\end{aligned}
$$

Therefore, in this symmetric case, the competitive equilibrium along the balanced growth path is characterized by a lower dimensional dynamic system of $\left(\hat{s}_{t}, \tilde{b}_{t}, \hat{a}_{t}, \hat{\gamma}_{H, t}, \xi_{t}, \hat{\gamma}_{e r, t}, \zeta_{t}, \hat{\gamma}_{\Phi, t}, \hat{h}_{t}, \hat{y}_{t}, \hat{q}_{t}\right)$.

\section{Appendix C. Derivation of the equilibrium currency return (6)}

Substituting the equilibrium detrended exchange rate (5) into the depreciation rate $\Delta \ln S_{t}$ gives

$$
\begin{gathered}
\Delta \ln S_{t}=\hat{\gamma}_{H, t}+\hat{\gamma}_{e r, t}-\hat{\gamma}_{\Phi, t}+\frac{\beta \eta-1}{\beta p_{h}^{*} y^{*}}\left(\tilde{b}_{t-1}-\tilde{b}_{t-2}\right)+\frac{\beta \eta-1}{1-\beta \eta(1-\lambda)}\left(\hat{a}_{t}-\hat{a}_{t-1}\right)+\frac{1-\kappa}{1-\kappa \rho_{h}}\left(\hat{h}_{t}-\hat{h}_{t-1}\right) \\
+\frac{\beta \eta-1}{1-\beta \eta \rho_{y}}\left(\hat{y}_{t}-\hat{y}_{t-1}\right)-\frac{\beta \eta-1}{1-\beta \eta \rho_{q}}\left(\hat{q}_{t}-\hat{q}_{t-1}\right)+\frac{\kappa \rho_{H}}{1-\kappa \rho_{H}}\left(\hat{\gamma}_{H, t}-\hat{\gamma}_{H, t-1}\right)+\frac{\kappa \rho_{e r}}{1-\kappa \rho_{e r}}\left(\hat{\gamma}_{e r, t}-\hat{\gamma}_{e r, t-1}\right) \\
-\frac{\kappa \rho_{\Phi}}{1-\kappa \rho_{\Phi}}\left(\hat{\gamma}_{\Phi, t}-\hat{\gamma}_{\Phi, t-1}\right)+\frac{\kappa}{1-\kappa \rho_{H}}\left(\xi_{t-1}-\xi_{t-2}\right)+\frac{\kappa^{2}}{1-\kappa \rho_{H}}\left(\xi_{t}-\xi_{t-1}\right)+\frac{\kappa}{1-\kappa \rho_{e r}}\left(\zeta_{t-1}-\zeta_{t-2}\right)+\frac{\kappa^{2}}{1-\kappa \rho_{e r}}\left(\zeta_{t}-\zeta_{t-1}\right) .
\end{gathered}
$$

Substituting eq. (B.13) into $\tilde{b}_{t-2}$ of the above equation and using the stochastic processes of the exogenous impulses provides

$$
\begin{aligned}
\Delta \ln S_{t} & =\frac{(\beta \eta-1)(\eta-1)}{\beta \eta p_{h}^{*} y^{*}} \tilde{b}_{t-1} \frac{(1-\kappa) \rho_{H}}{1-\kappa \rho_{H}} \hat{\gamma}_{H, t-1}+\frac{(1-\kappa) \rho_{e r}}{1-\kappa \rho_{e r}} \hat{\gamma}_{e r, t-1}-\frac{(1-\kappa) \rho_{\Phi}}{1-\kappa \rho_{\Phi}} \hat{\gamma}_{\Phi, t-1} \\
& -\frac{(1-\kappa)\left(1-\rho_{h}\right)}{1-\kappa \rho_{h}} \hat{h}_{t-1}+\frac{\beta \eta-1}{1-\beta \eta(1-\lambda)} \epsilon_{A, t}+\frac{\beta \eta-1}{1-\beta \eta \rho_{y}} \epsilon_{y, t}-\frac{\beta \eta-1}{1-\beta \eta \rho_{q}} \epsilon_{q, t}+\frac{1-\kappa}{1-\kappa \rho_{h}} \epsilon_{h, t} \\
+ & \frac{1}{1-\kappa \rho_{H}} \epsilon_{H, t}+\frac{1}{1-\kappa \rho_{e r}} \epsilon_{e r, t}-\frac{1}{1-\kappa \rho_{\Phi}} \epsilon_{\Phi, t}+\frac{1-\kappa}{1-\kappa \rho_{H}} \xi_{t-2}+\frac{\kappa(1-\kappa)}{1-\kappa \rho_{H}} \xi_{t-1}+\frac{\kappa^{2}}{1-\kappa \rho_{H}} \xi_{t} \\
& \quad+\frac{1-\kappa}{1-\kappa \rho_{e r}} \zeta_{t-2}+\frac{\kappa(1-\kappa)}{1-\kappa \rho_{e r}} \zeta_{t-1}+\frac{\kappa^{2}}{1-\kappa \rho_{e r}} \zeta_{t} .
\end{aligned}
$$

Finally, using the relationship of the root of the expectational difference equation of $\tilde{b}_{t},(\beta \eta-1)(\eta-1)=$ $\beta \eta p_{h}^{*} y^{*} \psi(1-\kappa)$, derives eq. (6).

\section{Appendix D. Data description and construction}

All data for the United States are distributed by Federal Reserve Economic Data (FRED), operated by the Federal Reserve Bank of St. Louis (http://research.stlouisfed.org/fred2/). The consumption data are constructed as the sum of the real personal consumption expenditures on non-durables and services. FRED, however, distributes only the nominal values of two categories of personal consumption expenditures as Personal Consumption Expenditure on Non-Durables (PCND) and Personal Consumption Expenditure on Services (PCESV). To construct the real series of two categories of personal consumption expenditure $C_{u s, t}$, we first calculate the share of the two nominal consumption categories in the nominal total personal 
consumption expenditure Personal Consumption Expenditure and then multiply the real total personal consumption expenditures, Real Personal Consumption Expenditures at Chained 2005 Dollars (PCECC96), by the calculated share. The output $Y_{u s, t}$ is employed Real Gross Domestic Product (GDPMC1). As the aggregate monetary supply $M_{u s, t}$ and the excess reserve, we employ St. Louis Adjusted Monetary Base (BASE) and Excess Reserves of Depository Institutions (EXCSRESNS). The nominal interest rate $r_{u s, t}$ is provided by three-month Treasury Bill (TB3MS).

As for the Japanese data, the series of the real consumption expenditures on non-durables and services, and real GDP are distributed by the Systems of National Accounts (SNA) database, released by Cabinet Office, Government of Japan. We combine the series from the data whose benchmark year is 2000 and the one whose benchmark year is 2005 in the first quarter of the year 1994 using the growth rate of the series of the benchmark year being equal to 2000. The Japanese monetary data are obtained from Bank of Japan website. We use Monetary Base (Reserve Requirement Rate Change Adjusted)/Seasonally Adjusted (X-12-ARIMA)/Average Amounts Outstanding as the money supply $M_{j p n, t}$, and calculate the excess reserve by subtracting Required Reserve (Average Outstanding) from Reserves/Average Outstanding. Only the nominal interest rate $r_{j p n, t}$ is downloaded Interest Rates, Government Securities, Treasury Bills for Japan (INTGSTJPM193N) from FRED.

Finally, the nominal exchange rate between the United States and Japan is employed Japan / U.S. Foreign Exchange Rate (EXJPUS) in the FRED database.

\section{References}

Backus, D.K., Smith, G.W., 1993, Consumption and real exchange rates in dynamic economies with non-traded goods, Journal of International Economics 35, 297 - 316.

Balke, N.S., Ma, J., Wohar, M.E., 2013, The contribution of economic fundamentals to movements in exchange rates, Journal of International Economics 90, 1 - 16.

Engel, C., 2014, Exchange rates and interest parity, in Gopinath, G., Helpman, E., and Rogoff, K. eds., Handbook of International Economics, vol 4, 453-522, North Holland/Elsevier, London.

Engel, C., West, K.D., 2005, Exchange rates and fundamentals, Journal of Political Economy 113, $485-517$.

Geweke, J.F., 1999, Using simulation methods for Bayesian econometric models: inference, development, and communication, Econometric Reviews 18, 1 - 126.

Kano, T., 2014, Exchange rates and fundamentals: closing a two-country model, Discussion Paper 2013-07, the Graduate School of Economics, Hitotsubashi University.

Meese, R.A., Rogoff, K., 1983, Empirical exchange rate models of the seventies, Journal of International Economics 14, 3-24. 
Nason, J.M., Rogers, J.H., 2008, Exchange rates and fundamentals: a generalization, Federal Researve Bank of Atlanta Working Paper 2008-16.

Sarno, L., Sojli, E., 2009, The feeble link between exchange rates and fundamentals: can we blame the discount factor?, Journal of Money, Credit, and Banking 41, 437 - 442.

Sargent, T.J., 1987, Macroeconomic Theory, second ed. Academic Press, San Diego, California.

Sims, C. A., 2001, Solving linear rational expectations model, Computational economics 20, $1-20$. 


\section{Table 1: Prior Distributions of Structural Parameters}

\begin{tabular}{|c|c|c|c|c|c|}
\hline & Parameters & Distribution & Mean & S.D. & $95 \%$ Coverage \\
\hline$\beta$ & Household Subjective Discount Factor & Uniform $(0,1)$ & - & - & {$[0.0250 .975]$} \\
\hline$\psi$ & Debt Elasticity of Risk Premium & Gamma & 0.010 & 0.001 & {$\left[\begin{array}{ll}0.008 & 0.012\end{array}\right]$} \\
\hline$\mu$ & Deterministic Augmented Monetary Base Growth & Gamma & 1.015 & 0.005 & {$\left[\begin{array}{ll}1.005 & 1.024\end{array}\right]$} \\
\hline$\lambda$ & Technology Diffusion Speed & Beta & 0.010 & 0.001 & {$\left[\begin{array}{ll}0.008 & 0.012\end{array}\right]$} \\
\hline$\rho_{H}$ & Monetary Base Growth AR(1) Coef. & Beta & 0.100 & 0.010 & {$[0.081 \quad 0.120]$} \\
\hline$\rho_{q}$ & RER AR(1) Coef. & Beta & 0.850 & 0.200 & {$\left[\begin{array}{ll}0.739 & 0.933\end{array}\right]$} \\
\hline$\rho_{\Phi}$ & Money Demand Growth AR(1) Coef. & Beta & 0.100 & 0.010 & {$\left[\begin{array}{ll}0.081 & 0.120\end{array}\right]$} \\
\hline$\rho_{e r}$ & Non Excess Reserve Growth $\mathrm{AR}(1)$ Coef. & Beta & 0.100 & 0.010 & {$\left[\begin{array}{ll}0.081 & 0.120\end{array}\right]$} \\
\hline
\end{tabular}

Note 1. The $\mathrm{AR}(1)$ coefficients of the transitory money and output shocks, $\rho_{h}$ and $\rho_{y}$ respectively, have the mass points of zero for identification.

Note 2. The standard deviations of all the structural shocks, $\sigma_{H}, \sigma_{A}, \sigma_{h}, \sigma_{y}, \sigma_{q}, \sigma_{\Phi}, \sigma_{e r}, \sigma_{\xi}, \sigma_{\zeta}$ have the identical inverse Gamma prior distribution, with a mean of 0.01 and standard deviation of 0.01 for the benchmark information set. 


\section{Table 2: Posterior Distributions of Structural Parameters}

\begin{tabular}{lcccc}
\hline Parameters & Mean & S.D. & 95 \% Interval \\
\hline \hline$\kappa$ & 0.961 & 0.003 & {$[0.955$} & $0.967]$ \\
\hline$\beta$ & 0.974 & 0.005 & {$[0.963$} & $0.984]$ \\
$\psi$ & 0.010 & 0.001 & {$[0.008$} & $0.012]$ \\
$\mu$ & 1.013 & 0.005 & {$[1.003$} & $1.022]$ \\
$\lambda$ & 0.010 & 0.001 & {$[0.008$} & $0.013]$ \\
$\rho_{H}$ & 0.091 & 0.009 & {$[0.074$} & $0.108]$ \\
$\rho_{q}$ & 0.944 & 0.014 & {$[0.918$} & $0.967]$ \\
$\rho_{\Phi}$ & 0.091 & 0.007 & {$[0.077$} & $0.106]$ \\
$\rho_{e r}$ & 0.094 & 0.008 & {$[0.079$} & $0.110]$ \\
$\sigma_{H}$ & 0.051 & 0.004 & {$[0.042$} & $0.059]$ \\
$\sigma_{A}$ & 0.009 & 0.001 & {$[0.008$} & $0.011]$ \\
$\sigma_{h}$ & 0.006 & 0.001 & {$[0.004$} & $0.009]$ \\
$\sigma_{y}$ & 0.005 & 0.001 & {$[0.004$} & $0.006]$ \\
$\sigma_{q}$ & 0.011 & 0.001 & {$[0.008$} & $0.014]$ \\
$\sigma_{\Phi}$ & 0.053 & 0.004 & {$[0.046$} & $0.061]$ \\
$\sigma_{e r}$ & 0.049 & 0.004 & {$[0.042$} & $0.057]$ \\
$\sigma_{\xi}$ & 0.018 & 0.002 & {$[0.013$} & $0.022]$ \\
$\sigma_{\zeta}$ & 0.017 & 0.002 & {$[0.012$} & $0.021]$ \\
\hline Marginal Likelihood & & 1528.968 & \\
\hline
\end{tabular}

Note 1: The marginal likelihoods are estimated based on Geweke's (1999) harmonic mean estimator. 


\section{Table 3: Forecast Error Variance Decompositions}

(a): Depreciation Rate $\Delta \ln S_{t}$

\begin{tabular}{lccccccccc}
\hline Periods & $\epsilon_{H}$ & $\epsilon_{A}$ & $\epsilon_{h}$ & $\epsilon_{y}$ & $\epsilon_{q}$ & $\epsilon_{\Phi}$ & $\epsilon_{e r}$ & $\epsilon_{\xi}$ & $\epsilon_{\zeta}$ \\
\hline Impact & 26.38 & 0.51 & 0.00 & 0.00 & 0.11 & 28.86 & 25.29 & 9.60 & 9.24 \\
1 & 26.38 & 0.51 & 0.00 & 0.00 & 0.11 & 28.86 & 25.29 & 9.60 & 9.24 \\
2 & 24.90 & 0.49 & 0.00 & 0.00 & 0.10 & 27.24 & 23.87 & 11.93 & 11.46 \\
3 & 24.89 & 0.48 & 0.00 & 0.00 & 0.10 & 27.23 & 23.87 & 11.94 & 11.47 \\
4 & 23.84 & 0.46 & 0.00 & 0.00 & 0.09 & 26.09 & 22.86 & 13.59 & 13.05 \\
8 & 23.84 & 0.46 & 0.00 & 0.00 & 0.09 & 26.09 & 22.85 & 13.59 & 13.05 \\
12 & 23.84 & 0.46 & 0.00 & 0.00 & 0.09 & 26.08 & 22.85 & 13.59 & 13.05 \\
40 & 23.84 & 0.46 & 0.00 & 0.00 & 0.09 & 26.08 & 22.85 & 13.59 & 13.05 \\
\hline
\end{tabular}

(b): Consumption Differential Growth $\Delta \ln C_{t}$

\begin{tabular}{lccccccccc}
\hline Periods & $\epsilon_{H}$ & $\epsilon_{A}$ & $\epsilon_{h}$ & $\epsilon_{y}$ & $\epsilon_{q}$ & $\epsilon_{\Phi}$ & $\epsilon_{e r}$ & $\epsilon_{\xi}$ & $\epsilon_{\zeta}$ \\
\hline Impact & 0.00 & 63.27 & 0.00 & 0.01 & 36.72 & 0.00 & 0.00 & 0.00 & 0.00 \\
1 & 0.00 & 63.12 & 0.00 & 0.01 & 36.87 & 0.00 & 0.00 & 0.00 & 0.00 \\
2 & 0.00 & 62.98 & 0.00 & 0.01 & 37.01 & 0.00 & 0.00 & 0.00 & 0.00 \\
3 & 0.00 & 62.86 & 0.00 & 0.01 & 37.13 & 0.00 & 0.00 & 0.00 & 0.00 \\
4 & 0.00 & 62.76 & 0.00 & 0.01 & 37.23 & 0.00 & 0.00 & 0.00 & 0.00 \\
8 & 0.00 & 62.43 & 0.00 & 0.01 & 37.56 & 0.00 & 0.00 & 0.00 & 0.00 \\
12 & 0.00 & 62.24 & 0.00 & 0.01 & 37.75 & 0.00 & 0.00 & 0.00 & 0.00 \\
40 & 0.00 & 61.94 & 0.00 & 0.01 & 38.05 & 0.00 & 0.00 & 0.00 & 0.00 \\
\hline
\end{tabular}

(c): TB differential $r_{t}$

\begin{tabular}{lccccccccc}
\hline Periods & $\epsilon_{H}$ & $\epsilon_{A}$ & $\epsilon_{h}$ & $\epsilon_{y}$ & $\epsilon_{q}$ & $\epsilon_{\Phi}$ & $\epsilon_{e r}$ & $\epsilon_{\xi}$ & $\epsilon_{\zeta}$ \\
\hline Impact & 1.00 & 2.54 & 1.43 & 0.00 & 0.00 & 1.08 & 1.04 & 47.35 & 45.57 \\
1 & 0.50 & 2.47 & 0.70 & 0.00 & 0.00 & 0.54 & 0.52 & 48.55 & 46.73 \\
2 & 0.32 & 2.37 & 0.45 & 0.00 & 0.00 & 0.35 & 0.33 & 49.01 & 47.17 \\
3 & 0.29 & 2.85 & 0.41 & 0.00 & 0.00 & 0.32 & 0.30 & 48.83 & 47.00 \\
4 & 0.29 & 3.50 & 0.41 & 0.00 & 0.00 & 0.31 & 0.30 & 48.50 & 46.68 \\
8 & 0.28 & 5.89 & 0.40 & 0.00 & 0.00 & 0.31 & 0.29 & 47.30 & 45.53 \\
12 & 0.28 & 7.99 & 0.39 & 0.00 & 0.00 & 0.30 & 0.29 & 46.25 & 44.51 \\
40 & 0.25 & 17.05 & 0.35 & 0.00 & 0.00 & 0.27 & 0.26 & 41.69 & 40.13 \\
\hline
\end{tabular}

Note 1: The FEVDs are evaluated at the posterior means of the structural parameters.

Note 2: All of the numbers in the table are of percentage. 


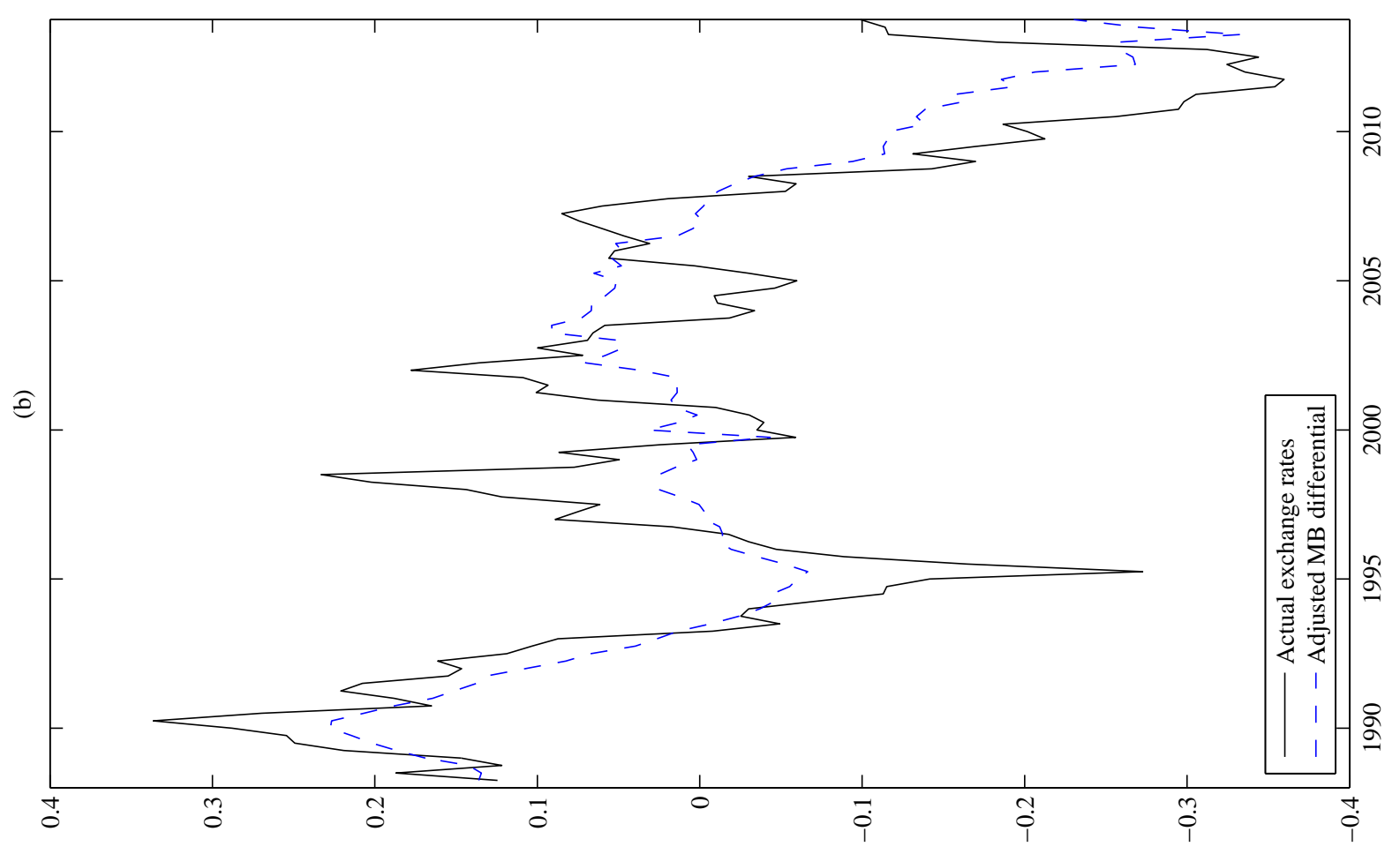

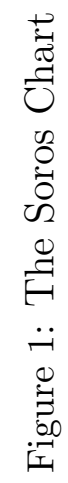

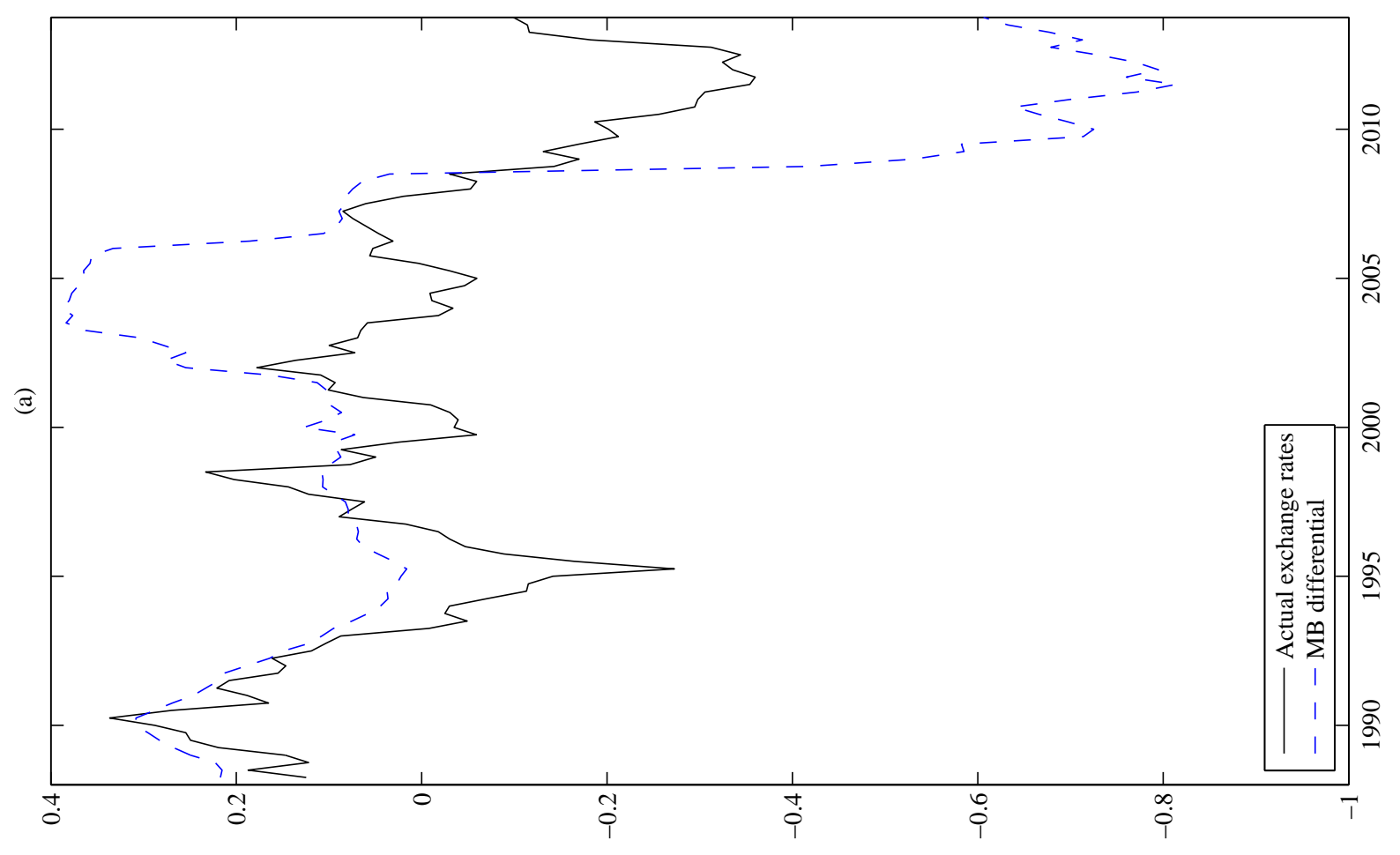




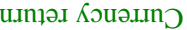

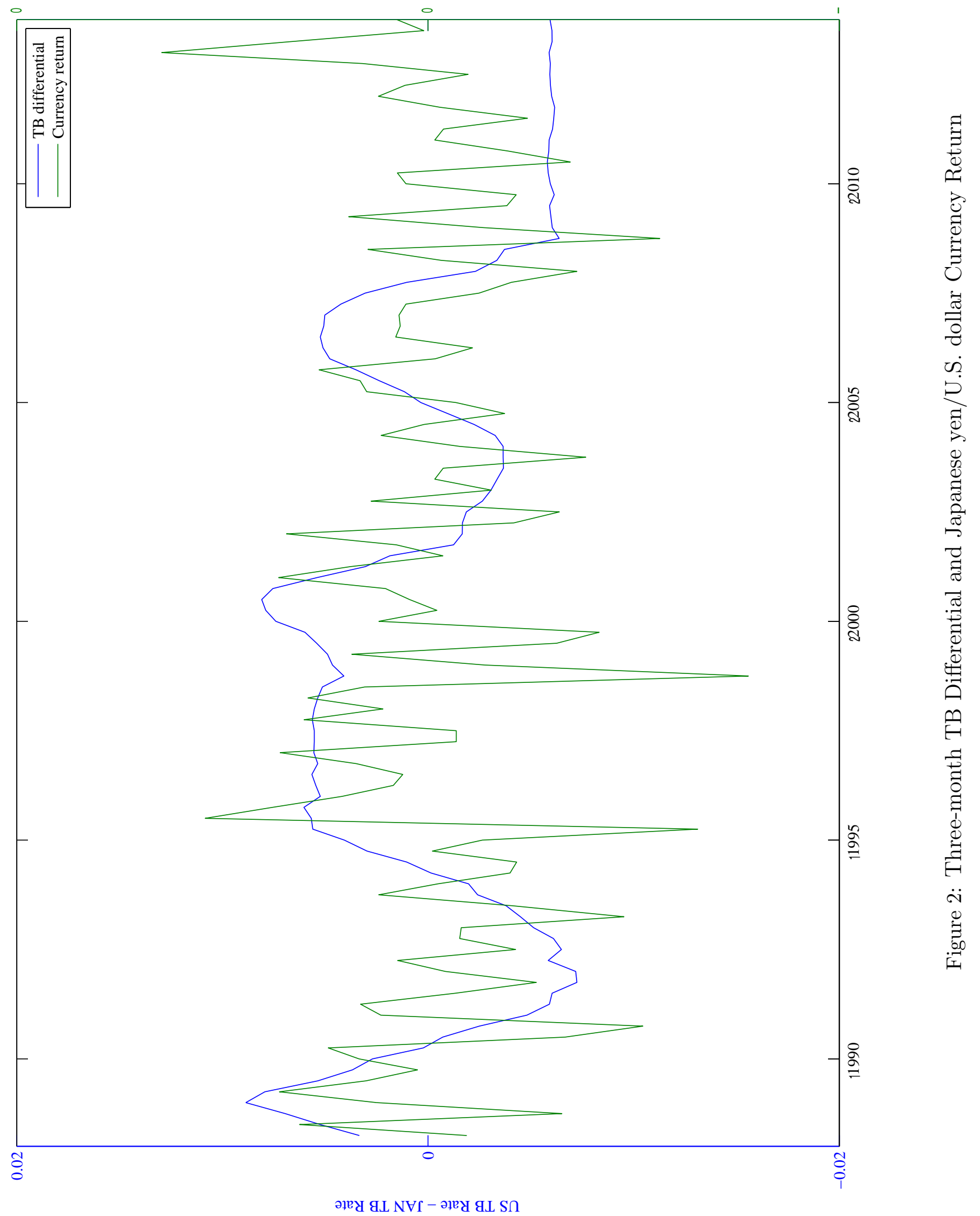




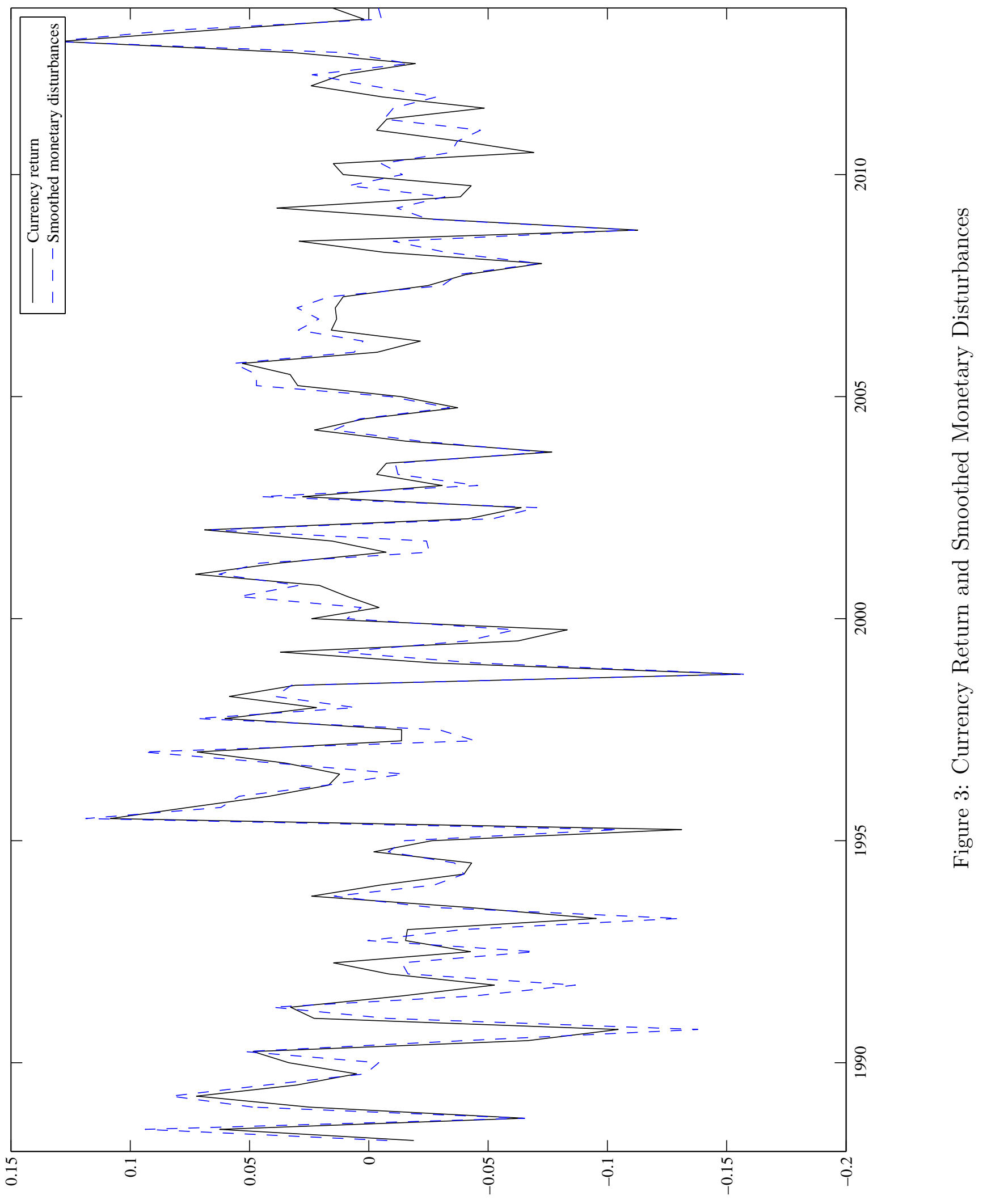




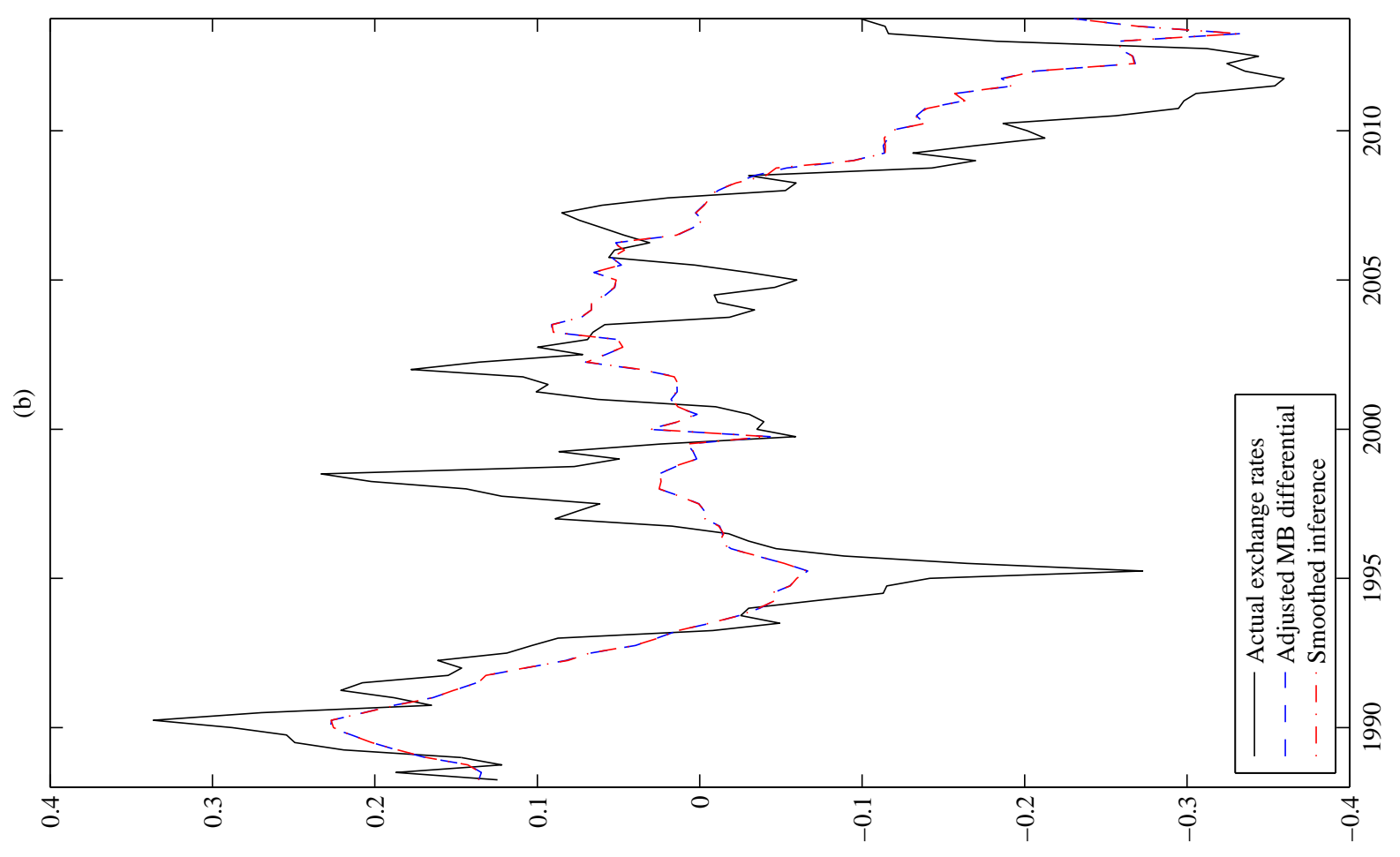

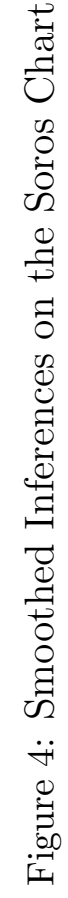

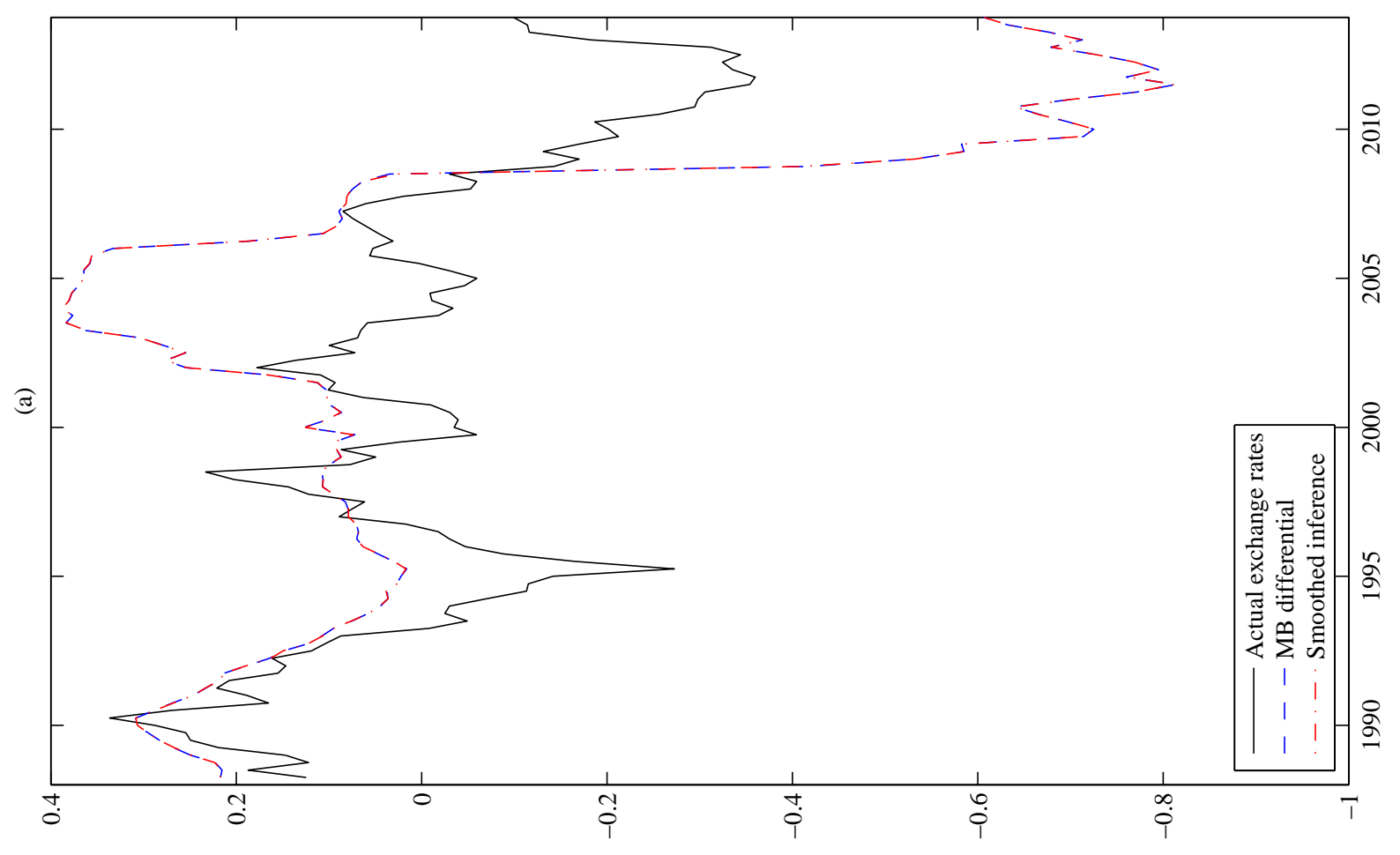




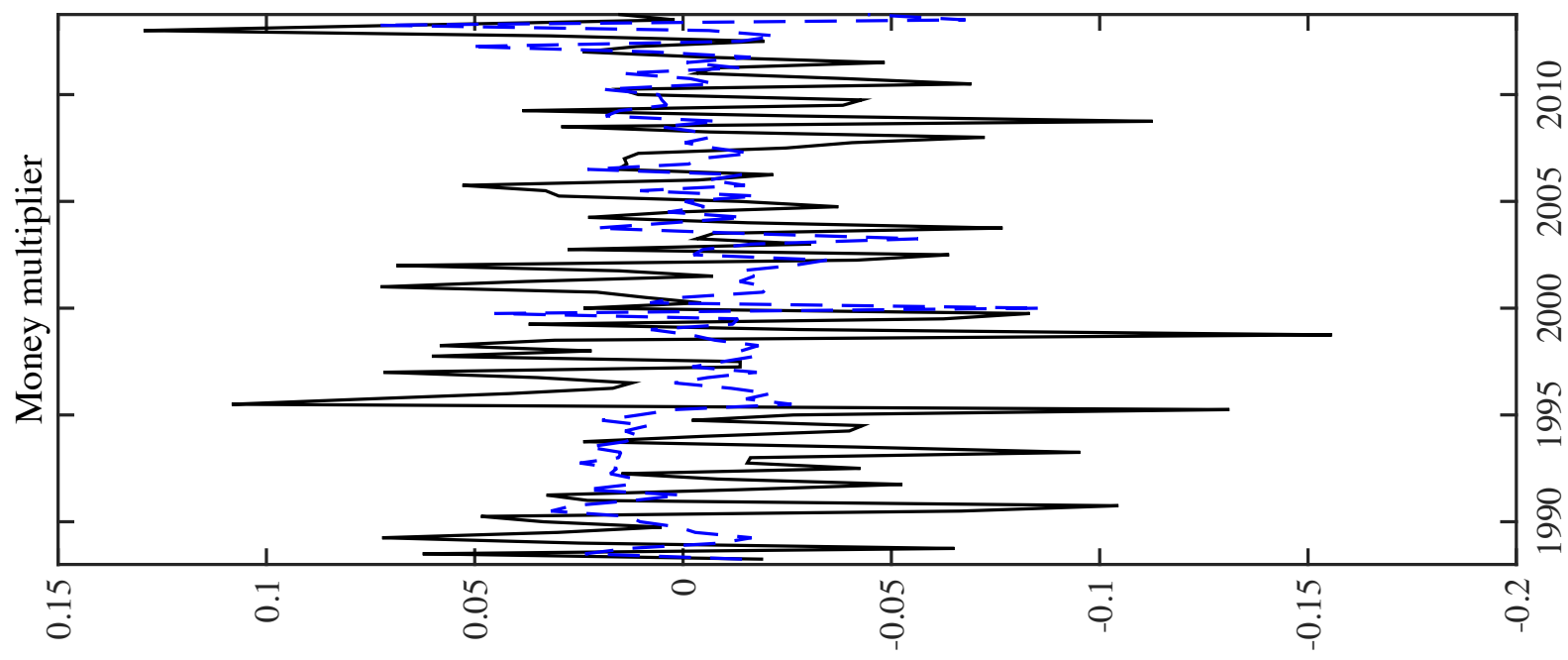

ت્ચ

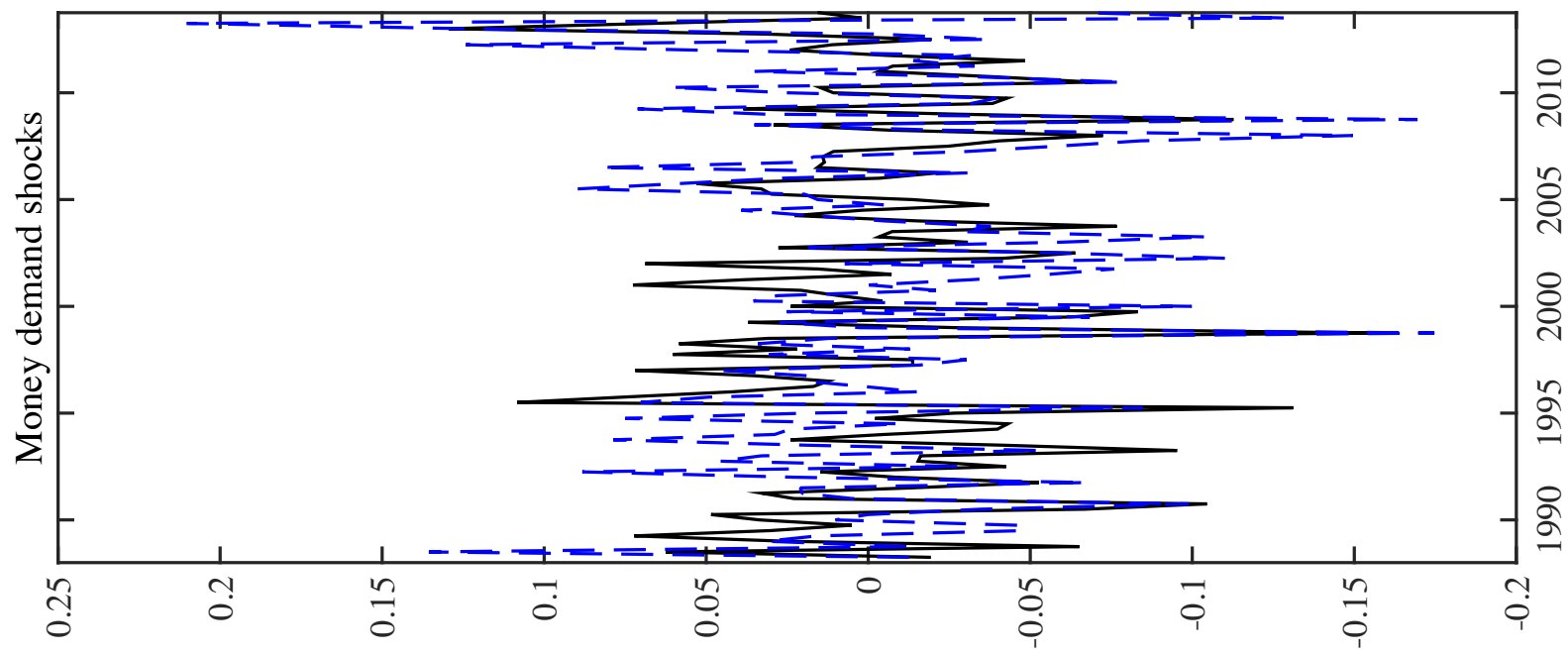

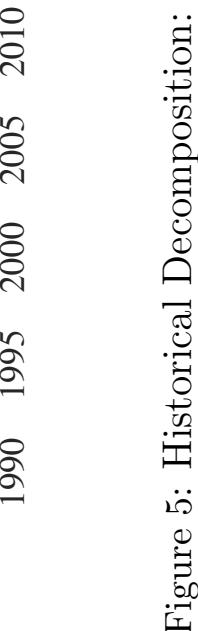

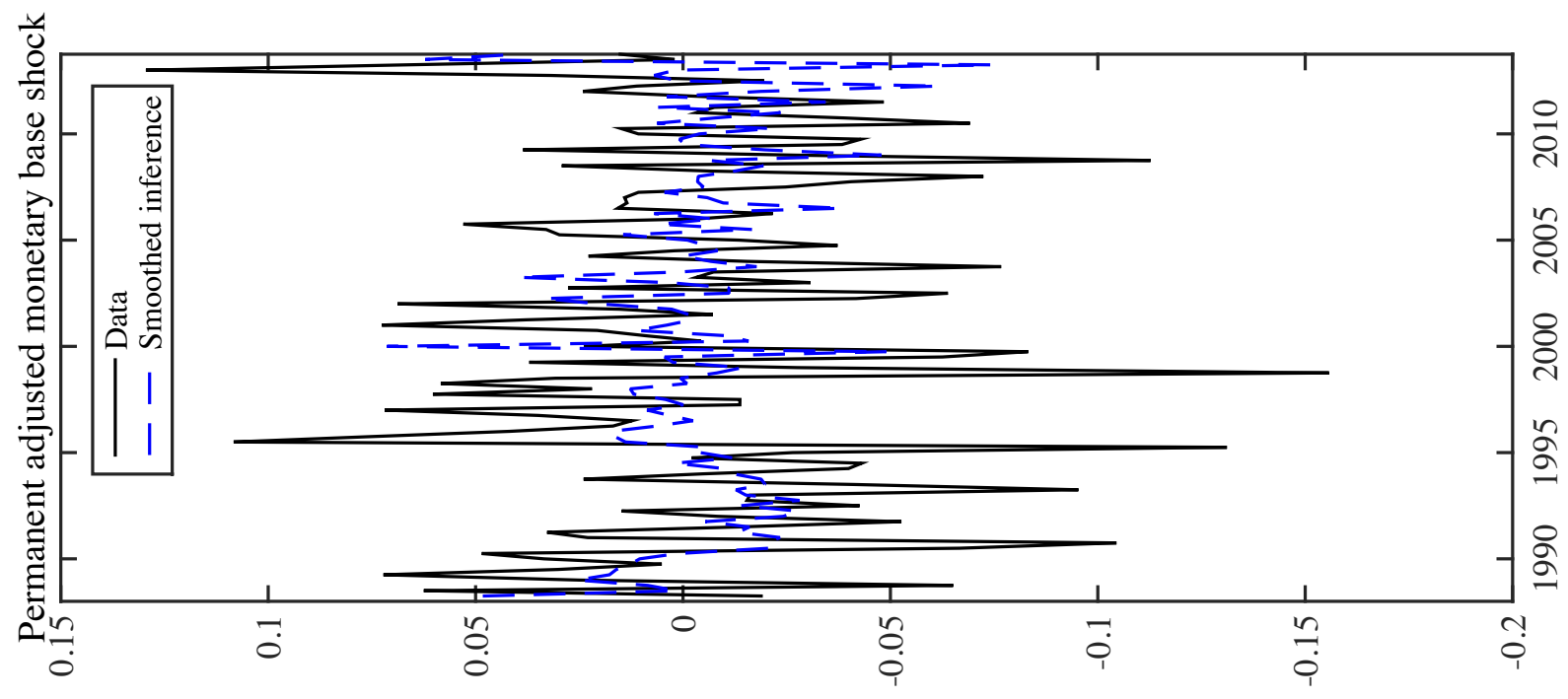




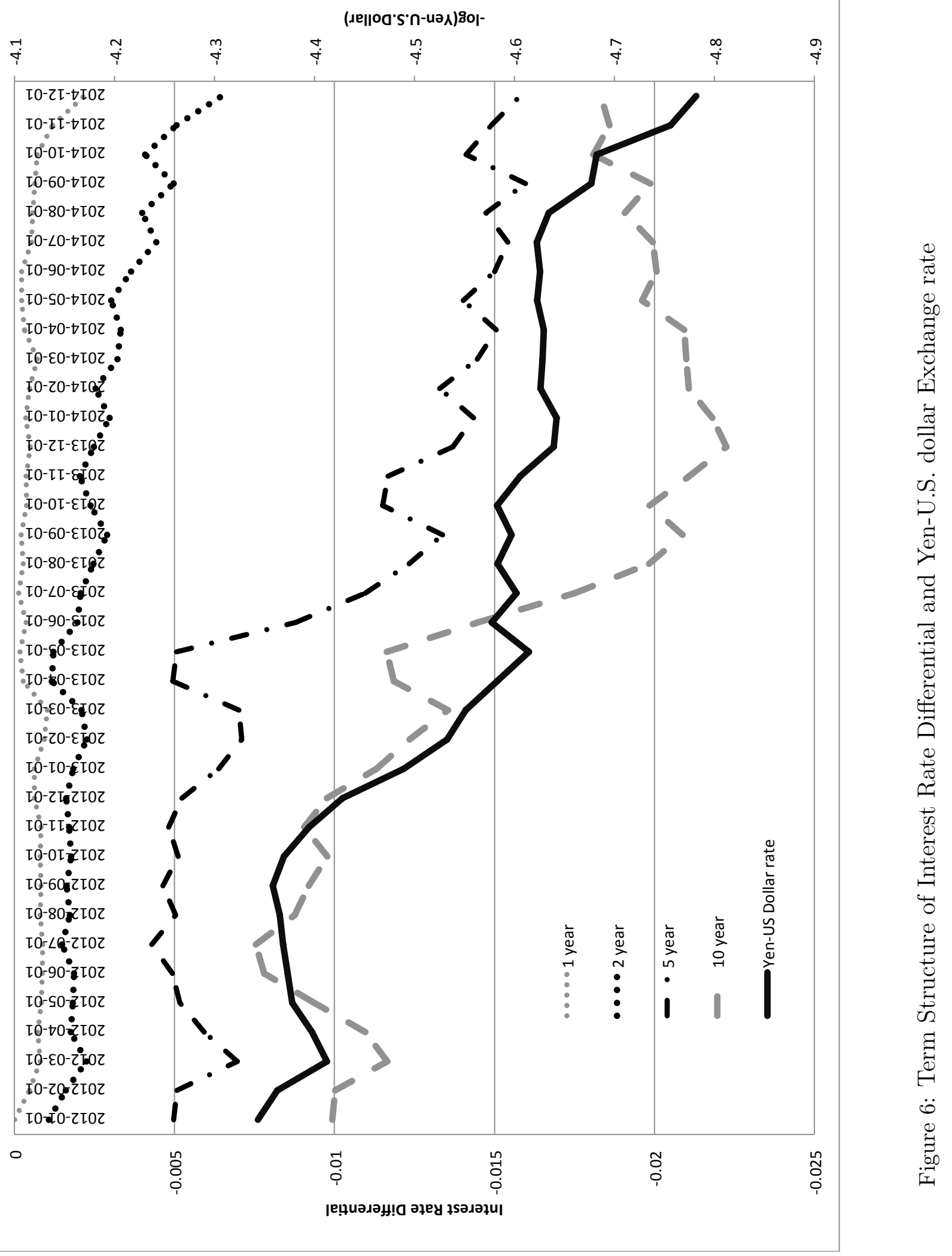

